\title{
Dynamic characteristics of a switch and crossing on the West Coast main line in the UK
}

\author{
Jou-Yi Shih ${ }^{1,2}$ (1) $\cdot$ Paul Weston ${ }^{1} \cdot$ Mani Entezami $^{1} \cdot$ Clive Roberts $^{1}$
}

Received: 17 February 2021/Revised: 29 December 2021 / Accepted: 29 December 2021/Published online: 29 January 2022

(C) The Author(s) 2022

\begin{abstract}
Railway switches and crossings constitute a small fraction of linear track length but consume a large proportion of the railway track system maintenance budget. While switch and crossing (S\&C) faults rarely prevent trains from running, switches and crossings are the source of many faults and need continual attention. On the rare occasions when trains are prevented from running the cost of the disruption is very high. Condition monitoring of the point operating equipment that moves the switchblades has been in use for many years but condition monitoring of the state of the switch in terms of the support and mechanical damage as trains pass over has only recently started to become possible. To this end, it is important to understand the correlation between $\mathrm{S} \& \mathrm{C}$ faults and sensor data that can detect those faults. This paper assesses some of the data collected from multiple sensors variously positioned on and around a switch and crossing on the UK mainline for a few days of normal train operation. Accelerometers, geophones, and strain gauges were installed at the locations where they were anticipated to be most useful. Forces at the load transfer point on the crossing nose were estimated from two separate strain gauge bridges and possible use of acceleration on the crossing is discussed. Correlations between different data are analysed and assessed and correlation between peak estimated load transfer forces and accelerations is presented. Based on the analysis, conclusions are drawn about the different types of dynamic
\end{abstract}

Jou-Yi Shih

jy.shih@zynamic.se

1 Birmingham Centre for Railway Research and Education, University of Birmingham, Birmingham B15 2TT, UK

2 Present Address: ZynaMic Engineering AB, 12070 Stockholm, Sweden information around S\&Cs that can be obtained from a variety of sensor types.

Keywords Railway - Accelerometer - Condition monitoring - Impact force $\cdot$ Switch and crossing $\cdot$ Strain gauge

\section{Introduction}

Switches and crossings (S\&Cs) provide the means by which trains running on one railway track are able to branch to another, providing essential operational freedoms. Continuously welded track has largely eliminated the need for joints in high-speed track but discontinuities around switches and crossings remain. Although designed with finely tuned 3D geometry to carry and guide wheelsets without loss of wheel load-bearing capacity, a real switch and crossing always introduces some irregularity. Repeated concentrated forces lead to the accumulation of damage and, subsequently, to the requirement for maintenance and repair. The resulting damage tends to degrade crossing geometry over time resulting in further increase in forces. Safety is taken care of by regular inspections for damage and checking that wear will not allow even a small risk of derailment. Regular inspections also flag up necessary repair work such as grinding, welding, or, ultimately, replacement. S\&Cs are more susceptible to damage than plain track, so its maintenance takes up a significant proportion of the maintenance budget available for the track system as a whole. 
Faults such as cracks, severe wear, poor support, and incorrect switchblade adjustment, amongst others [1, 2], may grow such as to require a temporary speed limit or, ultimately, costly S\&C replacement. Hence predictive maintenance using real-time condition monitoring has become popular so that maintenance activity can be planned more effectively. Interruptions to train operation can be reduced, and $\mathrm{S} \& \mathrm{C}$ service life increased when faults can be detected at an early stage of their development and promptly repaired. Consequently, system reliability can be improved, and the overall maintenance and delay cost can be decreased by good condition monitoring. Relatively recently, research on condition monitoring of switches and crossing components (other than the point operating machine) has become a topic of research by academics and railway practitioners. Examples of such research are described in the sequel.

In [3] site measurements using a three-axis accelerometer installed at the crossing nose with rail movement measured outside the track using a digital imaging device were compared with three different crossing conditions: repaired, worn, and damaged. The ratios of the 'mean' [assumed root mean square (RMS)] value of vertical to horizontal accelerations, the vertical acceleration distribution, and the wheel load transfer regions (indicated as the fatigue area) from individual wheelsets showed good potential for monitoring crossing condition. Rail displacements also showed good potential for monitoring the condition of the support at the crossing. However, the condition indicators are significantly influenced by the train speed and type, so choosing which data are considered and which are rejected is important for this system. A similar measurement method is described in [4] where a three-axis accelerometer and a displacement sensor at the crossing were similarly used. However, two inductive sensors were installed before the crossing nose to measure the train speed and detect individual wheelsets to select which train data is to be put forward for further analysis.

Another condition monitoring approach for crossings was proposed in [5] using accelerometers and quarterbridge strain gauges installed $50 \mathrm{~mm}$ below the running surface of the crossing frog. Although multiple sensors were installed, only data from one accelerometer and one strain gauge, furthest from the tip of the nose, were presented. The results show good potential for combining strain gauge and accelerometer observations for condition monitoring of a crossing nose. A similar condition monitoring approach using both acceleration and strain results was proposed in [6] and showed a strong relationship between the two. Strain gauges were also used in [7] but the strain gauges were installed on the underside of the crossing nose. The bending strain of the crossing showed potential for condition monitoring, but the results are significantly influenced by train speed and loading and also on the support stiffness, so it is difficult to set a threshold for condition monitoring.

A methodology for monitoring track stiffness using track vibration data independent of train speed and load has shown excellent potential for condition monitoring from site measurements [8]. However, the assumption of a homogenous Winkler foundation limits the method to use on plain track since at a S\&C the support typically varies widely from one bearer to the next. A low-complexity behavioural model for predictive maintenance of railway turnouts is proposed in [9, 10] and has shown good potential for monitoring ballast degradation. The method is based on rail receptance tests carried out at numerous locations along a turnout. Changes in the receptance over time can be used to monitor support degradation. However, this is not continual condition monitoring.

It is usual to monitor track geometry from dedicated track recording vehicles and becoming feasible to do so from in-service vehicles. However, geometrical data collected around $\mathrm{S} \& \mathrm{C}$ infrastructure is not generally used for assessment of their condition. A review of railway track geometry condition monitoring using in-service railway vehicles can be found in [11]. A vehicle-based condition monitoring system can monitor all the track that the vehicle covers compared to a track-based condition monitoring system (sensors installed on the track), but behaviour around S\&C is not always usable. Increased standard deviation of track irregularity is often associated with areas of ballast degradation but over $200 \mathrm{~m}$ section lengths [11], not so useful for a switch or crossing. However, switches and crossings frequently contribute strongly to increased standard deviations are generally discarded as anomalous data rather than being used to monitor S\&C. Problems obtaining repeatable sectioning for standard deviation computations and the relatively short lengths of switches and crossings potentially falling at the boundaries of sections makes the vehicle-based condition monitoring difficult [10]. Another vehicle-based track fault detection for rail corrugation, isolated rail defects, and loss of track vertical alignment was proposed in [12]. It was able to detect isolated track defects such as squats and bad joints. However, the results are affected by vehicle vibrations and there are issues with positional accuracy. Furthermore, it is important to classify the dynamic characteristics for different possible track situations such as rail joints or squats. Application to switches and crossings is still some way off.

Condition monitoring using strain gauges has been widely used for railway applications in both vehicle-based [13, 14] and track-based systems [15-19]. Impact or dynamic force is the most common output evaluated from strain gauge data although strain is the more relevant factor for material degradation. The monitoring thresholds need 
to be adjusted based on different track stiffness and traffic. A neat strain gauge configuration for use on the rail was proposed for measuring vertical and lateral impact forces $[18,19]$, but this was designed for use on plain track and is not directly applicable to S\&Cs as these do not have a uniform cross section. However, a modest change in the strain-gauge bridge configuration has the potential for $\mathrm{S} \& \mathrm{C}$ applications.

In summary, many approaches have been proposed using various sensors and data characteristics for monitoring different $\mathrm{S} \& \mathrm{C}$ faults and a track rather than vehiclebased monitoring system seems necessary. Accelerometers tend to be the most popular sensor type because of the relative ease of installation, their reliability and durability. However, the relationship between acceleration at one point and strain is very complicated at S\&Cs, depending on many poorly known and changing factors. On the other hand, strain gauges are becoming another popular sensor as the output is more directly relatable to strain and thus causes of S\&C failure. However, strain gauges are more difficult to install and less robust than accelerometers. Currently, strain gauges are generally used only on plain track. Embedding strain gauges into the crossing at the time of manufacture may be one way to provide more robust strain gauging of a crossing as the strain gauges can be inside the crossing where they are well protected.

The aim of this paper is to investigate the dynamic characteristics of a railway $\mathrm{S} \& \mathrm{C}$ when a train passes to assess the potential for a track-based condition monitoring system. A large number of sensors were installed on a main line switch and crossing to collect data from an S\&C and to try to see what can be observed. This paper discusses rail accelerations, bearer displacement, bending strain and forces and potential monitoring indices for some S\&C faults are then proposed.

\section{Trial on the West Coast mainline}

A rare opportunity to add sensors to a high-speed switch on the UK rail network arose so a short data collection exercise was carried out on a CEN56 113A shallow depth G type switch and its crossing, shown in Fig. 1. The switch radius is $1,650 \mathrm{~m}$ and the crossing angle is 1 in 28 . The bearer spacing is just under $700 \mathrm{~mm}$ and the track gauge is $1,435 \mathrm{~mm}$. The line speed for the through route is $200 \mathrm{~km} / \mathrm{h}$ but that for the diverging route is only about half as much.

A total of 45 channels of data collection was installed, including at the switch:
- 10 vertically sensing geophones on bearers from the switchblade toes onwards (numbered 1 to 10 on the plan),

- 2 IEPE accelerometers on one stock rail of the switch (1 vertical, 1 horizontal, numbered 33 and 34);

and at the crossing:

- 10 vertically sensing geophones on bearers around the crossing (numbered 11 to 20 on the plan),

- 8 IEPE accelerometers on the crossing (4 vertical, 4 horizontal), one set between the two shear strain gauges (numbered 35 to 42 in the plan),

- 3 strain gauge bridges attached to the crossing near to the expected point of impact (based on observation of the wear on the crossing nose).

Figure 2 shows the sensor placements and channel numbers for the measurements. The accelerometers and geophones are single point measurement devices with vertical or lateral sensing directions.

Three full-bridge strain gauge channels were installed in the gap between two successive bearers, around $0.5 \mathrm{~m}$ away from the crossing nose, indicated by the vertical dotted line in Fig. 2. This is close to the expected wheel/ rail transfer point, which is also the location on the crossing most prone to damage and ultimate failure [20-23]. Two full-bridges with four two-element $0 / 90^{\circ}$ strain gauges were installed on the neutral axis and between two bearers with the aim of measuring the pure shear strain at two cross sections, A and B. One full-bridge (C) using four single element strain gauges was installed at the lower edge of the crossing at the mid-point between A and B for measuring the pure bending strain. The distance between A and B is $220 \mathrm{~mm}$ with A closer to the crossing nose. The neat strain gauge configuration described in [16] for measuring vertical dynamic loading on the rail (on plain track) cannot be

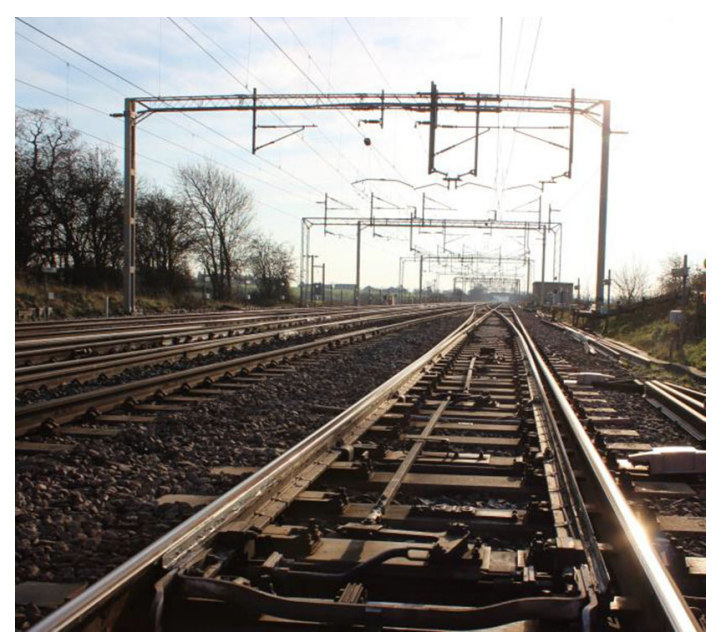

Fig. 1 Trial measurement test site 


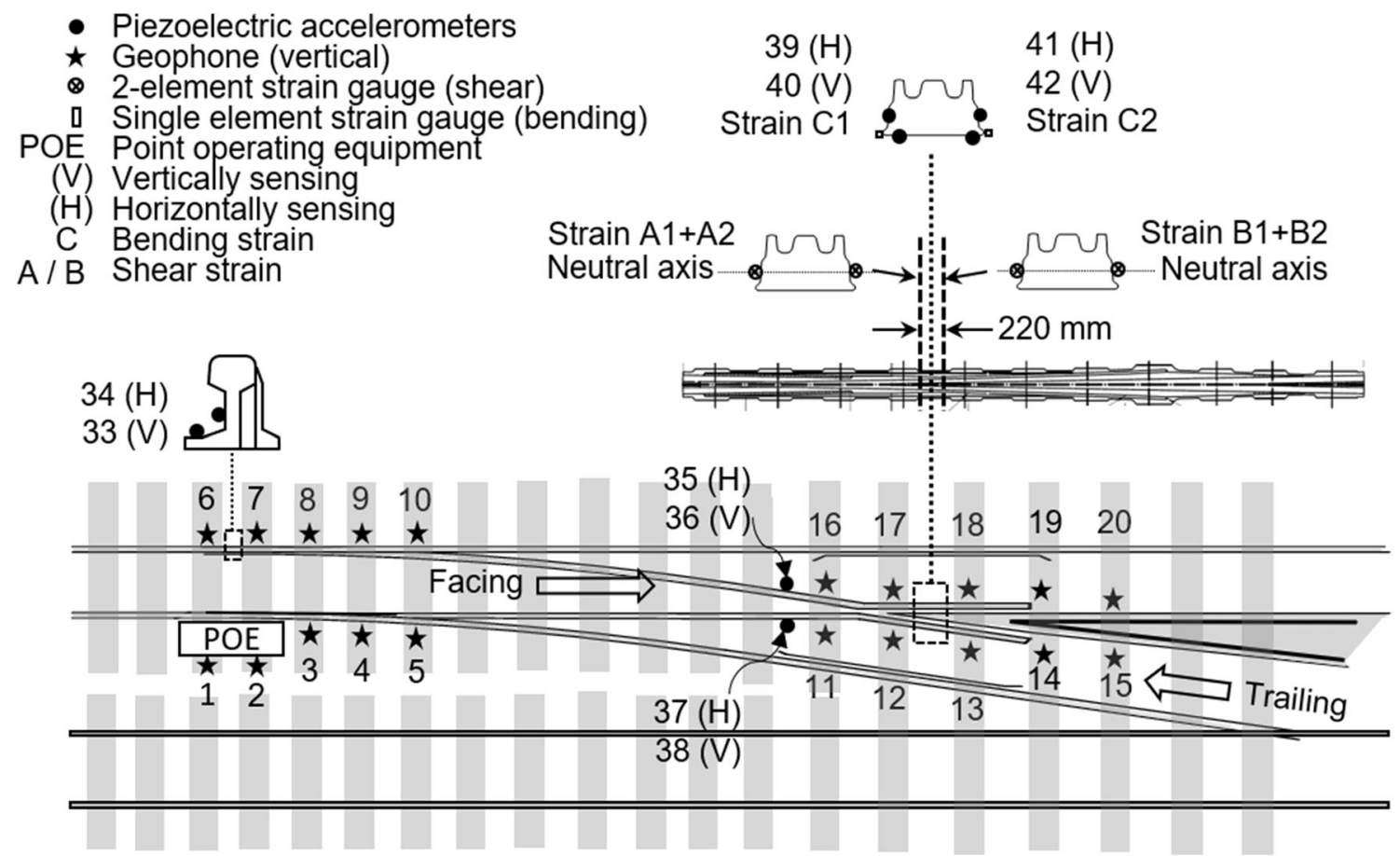

Fig. 2 Sensor layout around the S\&C

directly applied at the crossing as the cross section varies between the two bridge locations. However, the arrangement can be split into two separate bridges and re-combined, with appropriate weighting for each bridge reflecting the different cross sections, to obtain vertical dynamic force measurement between the bridge locations. Note that a) the wheel load transfer was assumed to happen between $\mathrm{A}$ and $\mathrm{B}$, which may not be true for all trains, and b) the sensor locations $\mathrm{A}$ and $\mathrm{B}$ have to be between two bearers. If the load transfer happens nearly over a bearer, the shear measurement method does not work as the force from the bearer supporting the rail is unknown.

All strain gauges, wiring pads, and the beginnings of the wires going to the main cable were liberally coated with a flexible rubber compound to provide waterproofing and some degree of mechanical support, as shown in Fig. 3. The opposite side is symmetric.

Table 1 shows some frequency-domain information for each sensor type. The rail-mounted IEPE accelerometers have a significantly higher range and bandwidth than the other sensors. The geophones on the bearers have sufficient bandwidth as the bearer frequencies of vibrations tend to be limited to a few hundred Hertz. The strain gauge bandwidth in the table is limited by the sampling rate, but as strain is effectively a displacement, it is naturally smaller for higher frequencies.

Twenty second bursts of data collection were triggered by vibration sensed on certain extremal sensors as a train approached. Three different passenger trains, Pendolino,

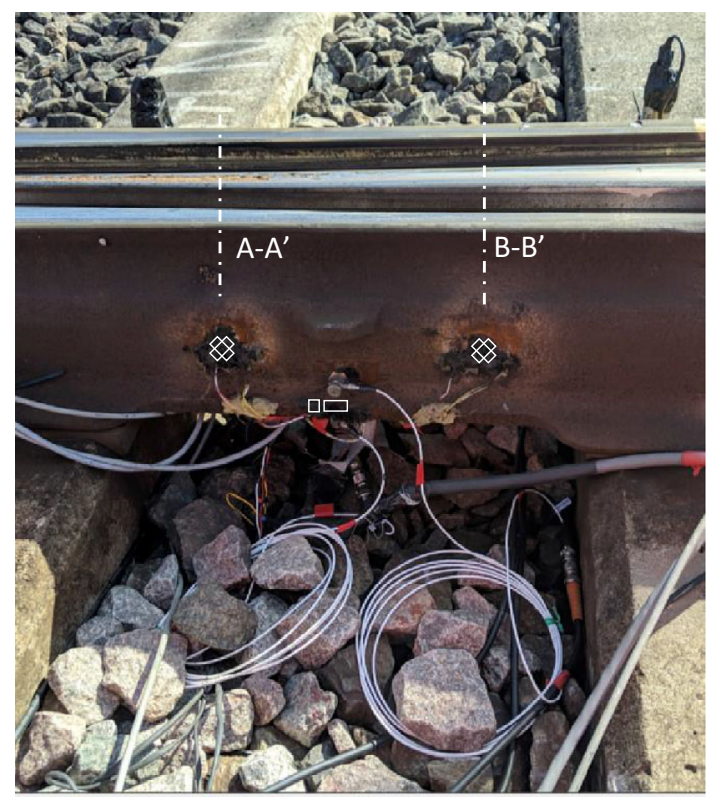

Fig. 3 Strain gauges (with rubberized coating) on crossing

Voyager and Class 350, as well as some freight trains, ran over this S\&C during a short data collection campaign. Data were collected from trains running on the through route in the facing direction and on the diverging line in the trailing direction, indicated in Fig. 2. No trains ran in the trailing direction for the through route, nor in the facing direction for the diverging route during the data collection period because of the way in which this set of points is 
Table 1 Sensor bandwidths

\begin{tabular}{llll}
\hline Sensor & Sampling rate $(\mathrm{kHz})$ & Sensor range & Frequency response $(\mathrm{Hz})$ \\
\hline Geophone & 16 & $\pm 0.4 \mathrm{~ms}^{-1}$ & $1-300$ \\
IEPE accelerometer & 50 & $\pm 6,000 \mathrm{~ms}^{-2}$ & $1-20,000$ \\
Strain gauge bridge & 16 & $\pm 5 \%$ & 8,000 \\
\hline
\end{tabular}

used. This affects the range of speeds seen as the line speed in the facing direction is $200 \mathrm{~km} / \mathrm{h}$ but in the trailing direction it is $105 \mathrm{~km} / \mathrm{h}$.

In the next section, the displacement and acceleration results are shown and contrasted for the switch and for the crossing. The strain gauge results are left until Sect. 4 .

\section{Displacement and acceleration results}

Vertical bearer displacements derived from geophones and accelerations from IEPE accelerometers on the rail are discussed in this section. The initial choice of sensors was guided by the literature, but the data collected from the trial site showed that some sensors needed more dynamic range. Figure 4 shows the geophones close to the crossing. The geophones near the switch are outside of the rails near the ends of the bearers.

\subsection{Displacement analysis using geophone data}

Vertical displacement was estimated from geophone data by the usual single integration with a zero-phase high-pass

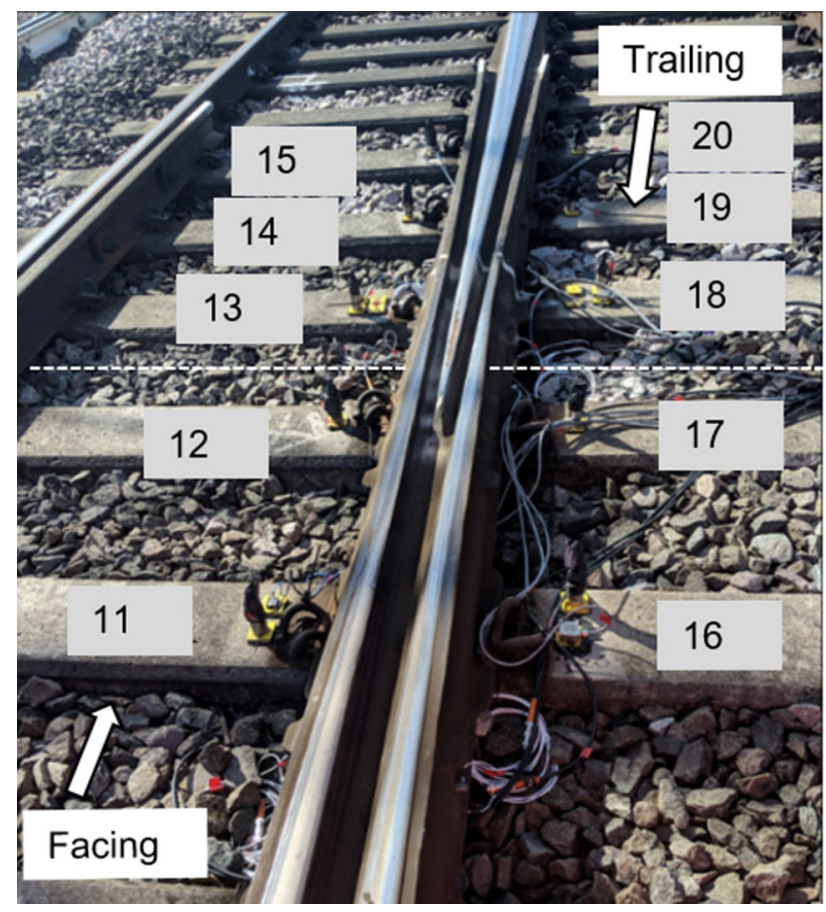

Fig. 4 Crossing nose and geophone channel numbers filter to suppress low-frequency drift and error. Phase shift around $1.0 \mathrm{~Hz}$ in the geophone internal circuitry significantly distorts the displacement results for trains passing at $105 \mathrm{~km} / \mathrm{h}$ or slower, so the phase shift of the geophone at lower frequencies was corrected using a filter applied in the time-reversed direction. The gain was left alone as the loss of gain at $1 \mathrm{~Hz}$ is not important compared to the distortion caused by the phase shift. The fastest, $200 \mathrm{~km} / \mathrm{h}$, trains have a carriage passing frequency of around $2 \mathrm{~Hz}$, whereas $105 \mathrm{~km} / \mathrm{h}$ trains have a carriage passing frequency of around $1 \mathrm{~Hz}$. The lower cut-off frequency of the geophones with the correction filters is around $0.5 \mathrm{~Hz}$, allowing through most of the displacement for trains moving as slowly as $51 \mathrm{~km} / \mathrm{h}$. Some of the geophones at the switch and crossing saturated for the highest speed trains.

Figure 5 compares the displacement results from geophones located towards each end of the bearers in the region of the switch toe for a $100 \mathrm{~km} / \mathrm{h}$ train. Each row contains the displacements from one bearer.

The peak-to-peak vertical displacements are 2 to $8 \mathrm{~mm}$. Displacements on the point operating equipment (POE) side (sensors 1-5) were smaller, perhaps because the POE is packed to keep the switch movement operating well. Significantly higher displacements were found on the end of the bearers away from the POE (sensors 6-10). The displacements identified from data from sensors 1 and 2 are around 10 times smaller than that found on the other side. Note that sensors 1 and 2 are placed outside of the POE (to avoid possible interference with the POE mechanical rods) so are further apart than other geophone pairs. The displacement from sensor 3, at one end of a particular bearer, is around 4 times smaller than the result from sensor 8 , at the other end of the same bearer. It is also notable that there is a considerable variation in the vertical displacement of neighbouring bearers over the 5 instrumented switch bearers. The movement on the side away from the POE peaks at bearer 2 and is assumed to have been significant on the bearers immediately ahead of the switch toe. It becomes relatively small again by the end of the instrumented bearers. The POE side vertical motion is tiny at bearers 1 and 2, where the POE is located, and largest at bearer 4. By bearer 5, the POE and opposite side are moving more or less together in the vertical direction. The differences seen between the two sides are potentially important as it imposes a geometrical twist into the loaded 


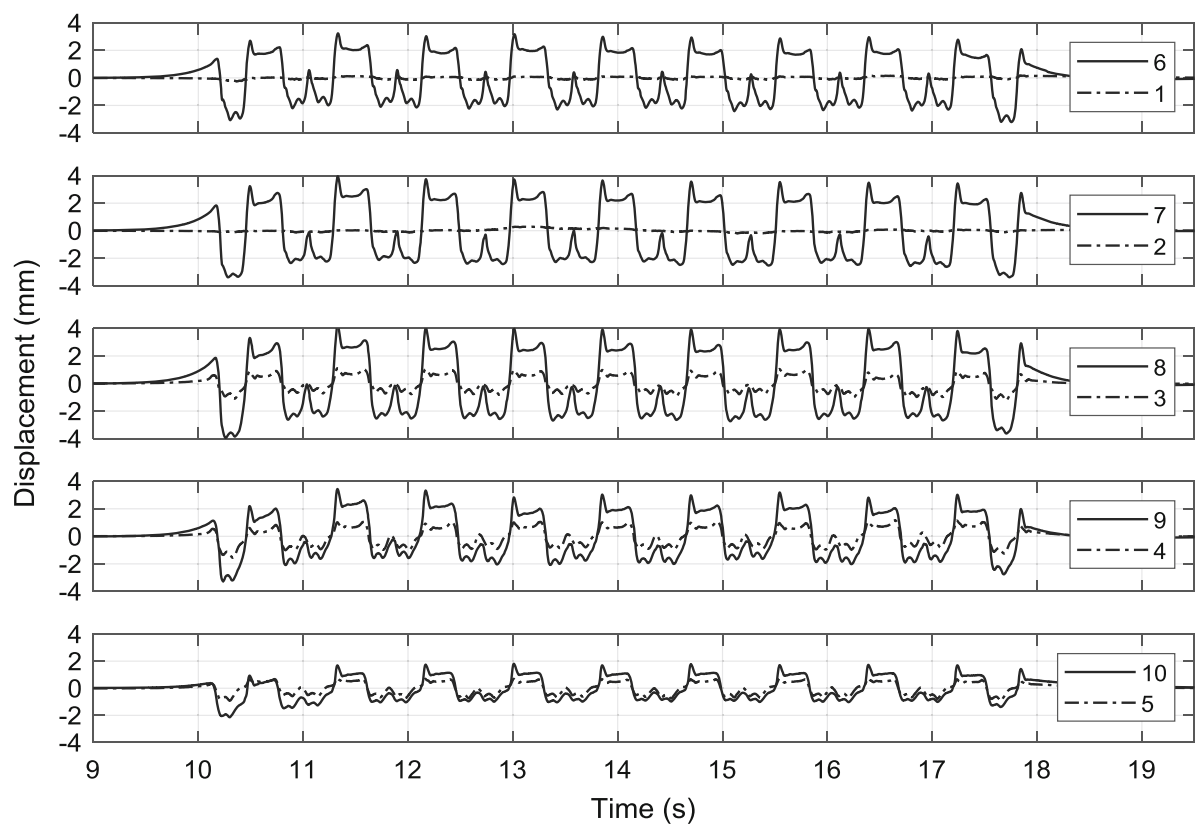

Fig. 5 Geophone-derived displacement at the switch at $100 \mathrm{~km} / \mathrm{h}$ : 1-5 on POE side; 6-10 opposite POE side (trailing diverging route)

track. Monitoring with a single sensor on one end or at the middle of a bearer is not sufficient, at least in this example. On the test site, the movement observable from the accessible cess area the tracks would show the POE side which is not moving much, whereas the unseen opposite side is moving considerably.

In contrast, the displacement results from each side of the crossing are found to be similar on each bearer for each train, as shown in Fig. 6 (note the smaller vertical scale compared to the switch results). Although the sensors are located either side of the crossing with about one third of the separation of the pairs of sensors on the switch bearers, the similarity in motion indicates that the bearers are not rotating in the same way as many of the switch bearers. This may be partly because these bearers are long bearers, extending underneath two tracks. The track stiffness at a crossing is typically higher than at a switch [24]. The vertical motion at the crossing bearers is from 1.5 to $3 \mathrm{~mm}$.

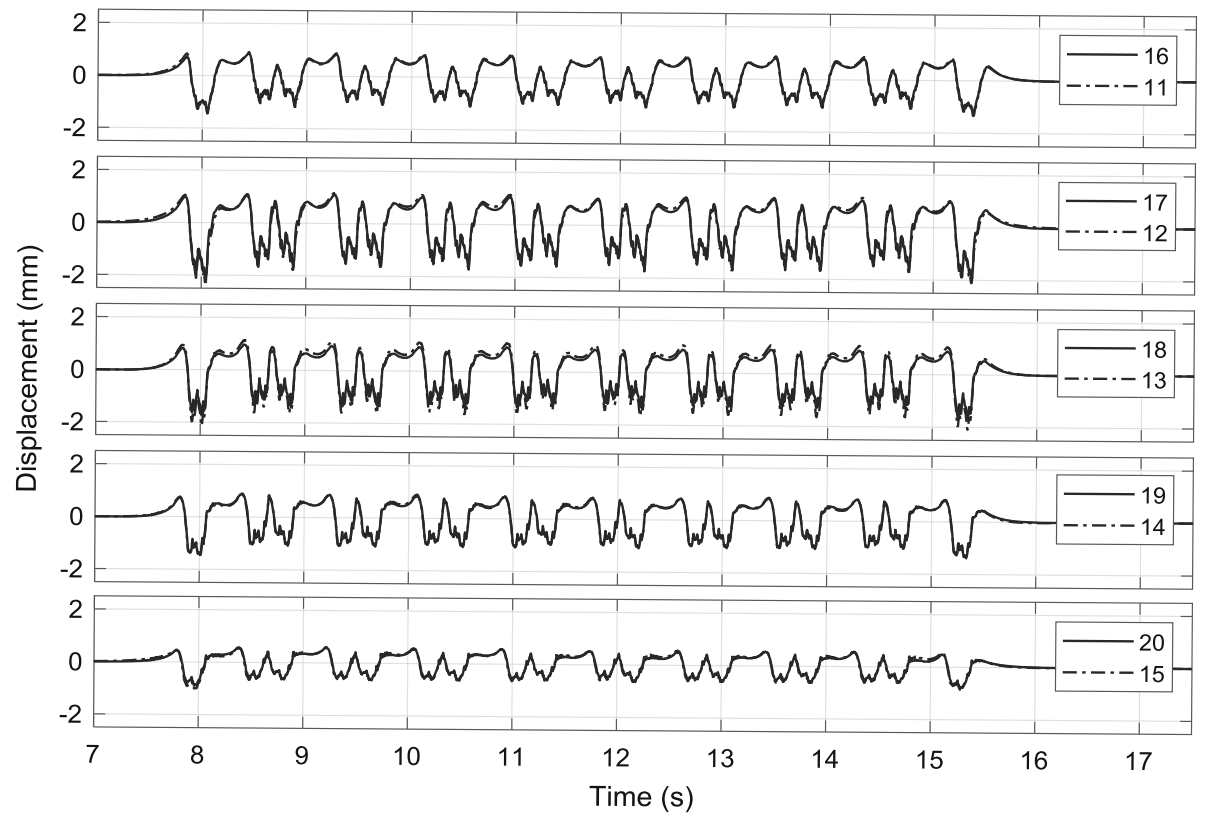

Fig. 6 Geophone-derived displacements at crossing at $100 \mathrm{~km} / \mathrm{h}: 11-15$ on one side; $16-20$ on the other side (trailing diverging route) 
For trains travelling at the line speed of $200 \mathrm{~km} / \mathrm{h}, 80 \%$ of the geophones at the switch and the geophones on the three middle bearers at the crossing reached their saturation limits, between 0.3 and $0.4 \mathrm{~ms}^{-1}$. This made the displacement reconstruction unusable. The geophone output signal recovery following saturation events is slow because of the response of the $1 \mathrm{~Hz}$ compensation circuitry integrated into the geophone. Therefore, the geophones used were unable to return displacement information for line speed trains travelling in the through direction.

The general approach to condition monitoring based on vertical bearer displacement is to look at the peak-to-peak movement. Large movements are considered to be bad, suggesting voiding. The experimental results at the trial switch and crossing show that vertical motion across the length of a bearer is not necessarily uniform, so placing one sensor on a bearer may not be sufficient. The results also show that the vertical motion of the bearers can vary significantly from one bearer to the next, so measuring the displacement of one 'key' bearer may not be enough.

\subsection{Accelerometers mounted directly onto the rails or crossing}

IEPE accelerometer bases were glued to the rails, or to the cast crossing, to sense vertical or lateral motion. The sensors need a high bandwidth to capture the accelerations on the rails with the $20 \mathrm{kHz}$ bandwidth arguably not enough to capture all acceleration. The bandwidth extends down to about $1 \mathrm{~Hz}$ so constant gravity is not sensed. The accelerations were found to be within the sensor range of $\pm 6,000 \mathrm{~ms}^{-2}$ almost all the time.

Rail and wheel roughness and discontinuities such as joints contribute to this acceleration. The largest accelerations are expected to come from either from damaged wheelsets or from impacts at the crossing as the load transfers from the wing rails to the crossing nose, or vice versa, or if a wheel hits the crossing nose. Accelerations in the hundreds of Hertz and above arising at one location rapidly travel along the metal to be picked up, somewhat reduced in amplitude, by neighbouring sensors. Thus, as the frequency increases the accelerometer becomes less able to localize the source of the acceleration. This can be a benefit as an impulsive acceleration in one place can be picked up at another location, or a problem when wheels passing over a joint generate impulsive acceleration that travels to other sensors causing confusing readings. There are also implications for trying to use acceleration information to estimate forces on parts of the structure as the simple formula 'force equals mass times acceleration' doesn't hold. Instead, the relationship between force and acceleration is one of accelerance or similar frequencydependent relationships [25]. Multiple wheels near the crossing at the same time generate a complex acceleration at each and every location.

Vertically sensing accelerometers 40 and 42 are expected to be most representative of the crossing condition being located around $0.5 \mathrm{~m}$ after the crossing nose (Fig. 2), close to where the load transfer occurs. Sensors 36 and 38 are positioned about $1 \mathrm{~m}$ ahead of the crossing nose to investigate the possibility of capturing dynamic behaviour a little way distant from the crucial location. Furthermore, accelerations in the vertical and horizontal directions are compared to investigate the potential of rail accelerations for monitoring the crossing condition.

\subsubsection{High accelerations in the vertical direction at the crossing}

The vertically sensing IEPE accelerometers on the crossing are glued underneath each side of the crossing, one pair near the expected load transfer point $0.5 \mathrm{~m}$ beyond the crossing nose and one pair about $1 \mathrm{~m}$ before the crossing nose.

Figure 7 shows the accelerations on the crossing from sensors 36 and 38 when a $100 \mathrm{~km} / \mathrm{h}$ train passes. The raw acceleration is on the top with versions low pass filtered at $5 \mathrm{kHz}, 1 \mathrm{kHz}$ and $200 \mathrm{~Hz}$ shown below. Sensor 36 is on the left, sensor 38 on the right. Figure 8 shows the same but from sensors 40 and 42 . The part of the train shown is most clear in the bottom right-hand side of Fig. 8 showing the leading bogie with two wheelsets followed by two bogies close together, the end of the leading vehicle and the front of the second vehicle, followed by the trailing bogie of the second vehicle.

There is a considerable build-up of acceleration in the unfiltered (and hence higher frequency content) in sensors 36 and 38 with a couple of large accelerations well before the leading wheelset arrives at the sensor. The unfiltered acceleration at sensor 38 shows a large value around 9, 7.6 and $7.8 \mathrm{~s}$. These are found also in sensor 40 . They are visible but significantly smaller in 36 and 42 . Whatever these peak accelerations represent, they do not seem to correspond to wheelsets and are well above $10 \mathrm{kHz}$ oscillations. Once filtered below $5 \mathrm{kHz}$ these high accelerations disappear. This means that the frequency range is important to the peak-to-peak acceleration seen. At higher speeds, the wheelsets are more clearly differentiated from other effects.

The cause of this is unknown. It is tempting to suggest wheel damage, or a joint in the crossing, but these possibilities do not fit with data from other trains. The highfrequency results from sensors 38 and 40 are similar with sensor 40 having slightly smaller acceleration. Although 36 and 38 are very close together, 36 does not see the highfrequency spikes seen in 36 . The reason for this is not 

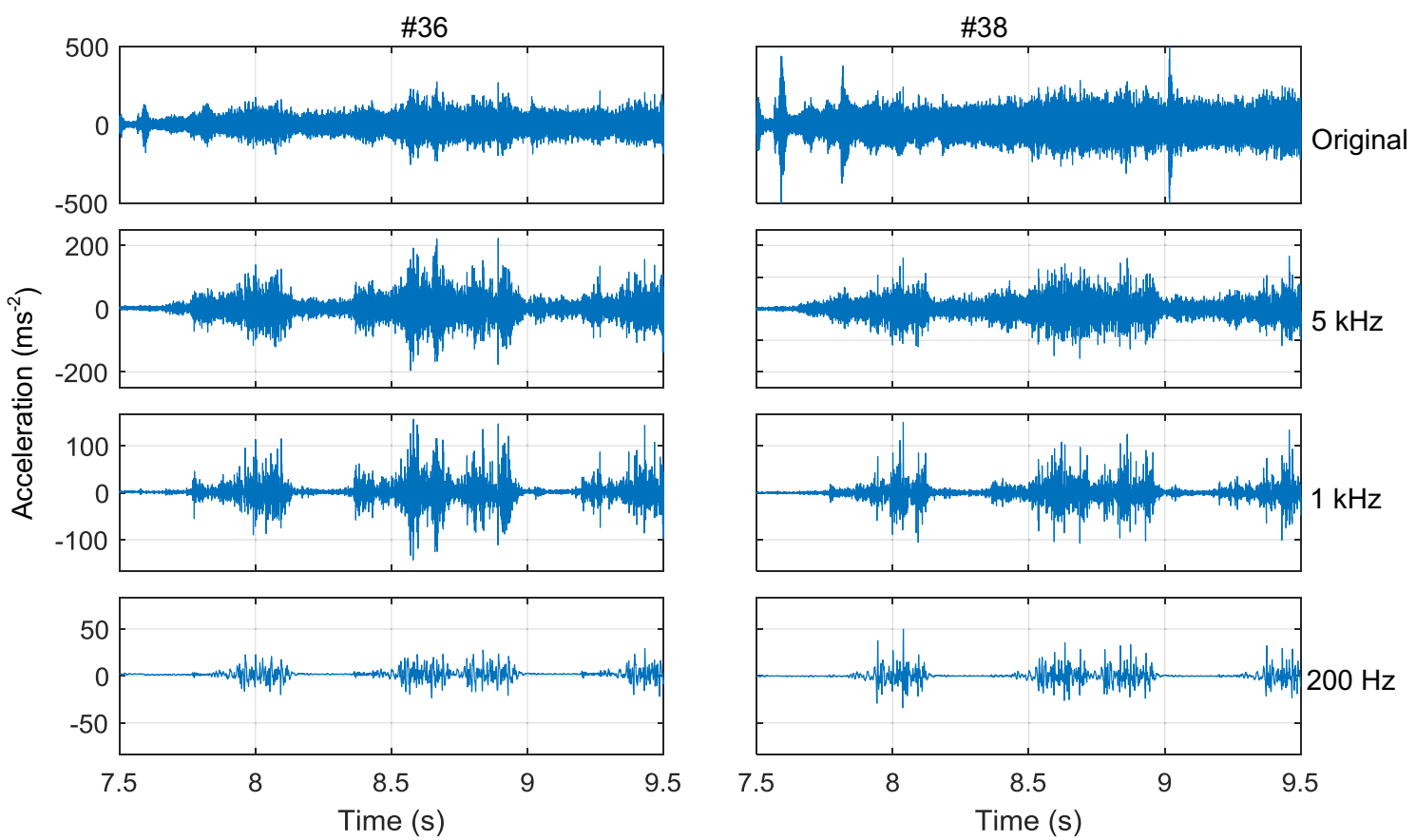

Fig. 7 Vertical acceleration with various low-pass filters, sensors 36 and 38, at $100 \mathrm{~km} / \mathrm{h}$ (trailing diverging route)
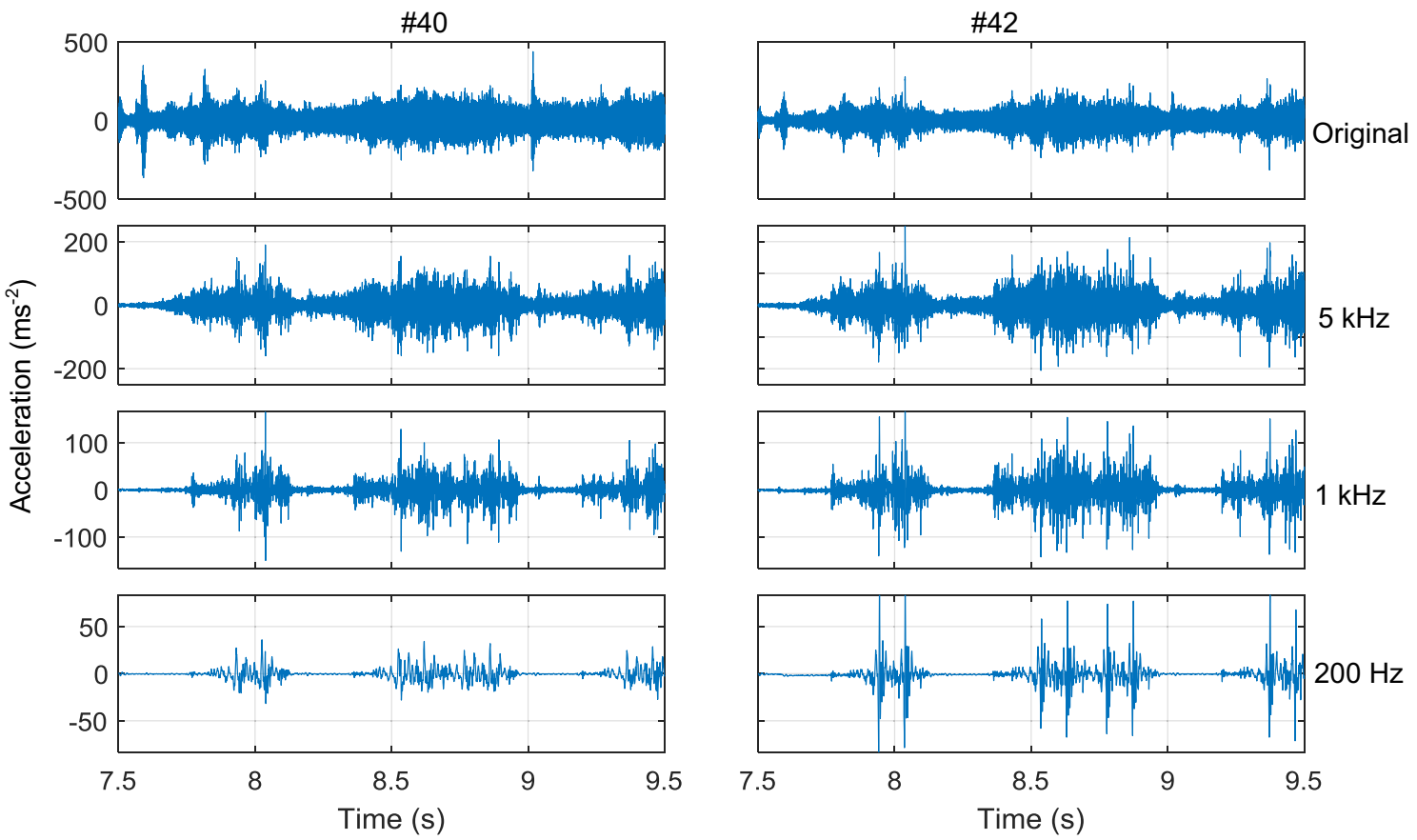

Fig. 8 Vertical acceleration with various low pass filters, sensors 40 and 42, at $100 \mathrm{~km} / \mathrm{h}$ (trailing diverging route)

known. Similarly, sensors 40 and 42 are close together but sensor 40 senses the higher frequency content with a large amplitude while the lower frequency content is sensed by sensor 42 . It is possible for sensor 42 to see more movement than sensor 40 at $200 \mathrm{~Hz}$ and below if the crossing itself does not just move vertically but also has a rotational motion. Sensors 40 and 42 are laterally separated by about $350 \mathrm{~mm}$. A small rotational adjustment when the load transfers from the crossing nose to the wing rail or the other way around could explain the observed behaviour.

The acceleration tends to reach larger values as the bandwidth increases. The localization of the acceleration to 
the wheelsets is best at the lower frequencies. The higher frequencies travel best along the rails. The RMS acceleration gives a result that depends on the chosen bandwidth and on the sensor location.

Figures 9 and 10 show vertical acceleration at sensors $36,38,40$ and 42 for a train travelling over the crossing at $177 \mathrm{~km} / \mathrm{h}$.

The accelerations are much larger at $177 \mathrm{~km} / \mathrm{h}$ than at $105 \mathrm{~km} / \mathrm{h}$. There is a sudden offset around $11.95 \mathrm{~s}$ in sensor 40 . This may be simply caused by a loose connection to the IEPE sensor causing a momentary disconnection that results in a loss of dc power or might be evidence of rectification error. The acceleration in the two sides is similar but not the same.

The results from sensors $36,38,40$ and 42 are shown for a $200 \mathrm{~km} / \mathrm{h}$ train in Figs. 11 and 12. The results are confusing. A strong acceleration at sensor 38 at $11.7 \mathrm{~s}$ in the original signal corresponds to the second wheelset on the leading bogie. It is randomly valued for different frequency ranges and positions. There is a new acceleration between two bogies, particularly in sensor 40 , as if there is an extra wheelset. This must come from somewhere, but where is not known. It could potentially arise from a wheel defect, but this is not known. Sensor 40 has a problem with offset as seen in the bottom left of Fig. 12. This sensor is believed to have a loose connection.

The vertical accelerations seen on the metalwork of the crossing have been compared. The accelerations on each side of the crossing are ostensibly similar but the accelerations near the transition point are generally larger, but not for the higher frequency content. The two sides near the load transition point show possible rotation of the crossing on load transfer. The acceleration range is highly dependent on frequency, as well as on sensor position, train type, and train speed. A sudden high acceleration could be from some distance from the sensor in which case the peak level of acceleration at a sensor does not capture the acceleration at the original source. The RMS and peak-to-peak acceleration are highly dependent on the chosen bandwidth. Acceleration depends on the local support details including rail pads, the sleepers, ballast and the ground condition. It is not, in the view of the authors, a good quantity to measure for condition monitoring. This does not preclude the use of displacement derived from acceleration.

In summary, a large measuring range, around $\pm 5,000 \mathrm{~m} / \mathrm{s}^{2}$ is required to capture the high impacts through the rail accelerations. To identify a faulty train, a frequency range of $20 \mathrm{kHz}$ is needed. Unwanted impacts such as wheels passing over joints or a damaged wheel profile can be eliminated using a low-pass filter. The acceleration results at $1 \mathrm{~m}$ away are not representative to the result at the crucial location. Eventually, the maximum acceleration becomes the same when $1,000 \mathrm{~Hz}$ low-pass filter is applied for different datasets with the same train speed. This may be used for monitoring the crossing condition; however, the use of low-pass filter may lose the important high-
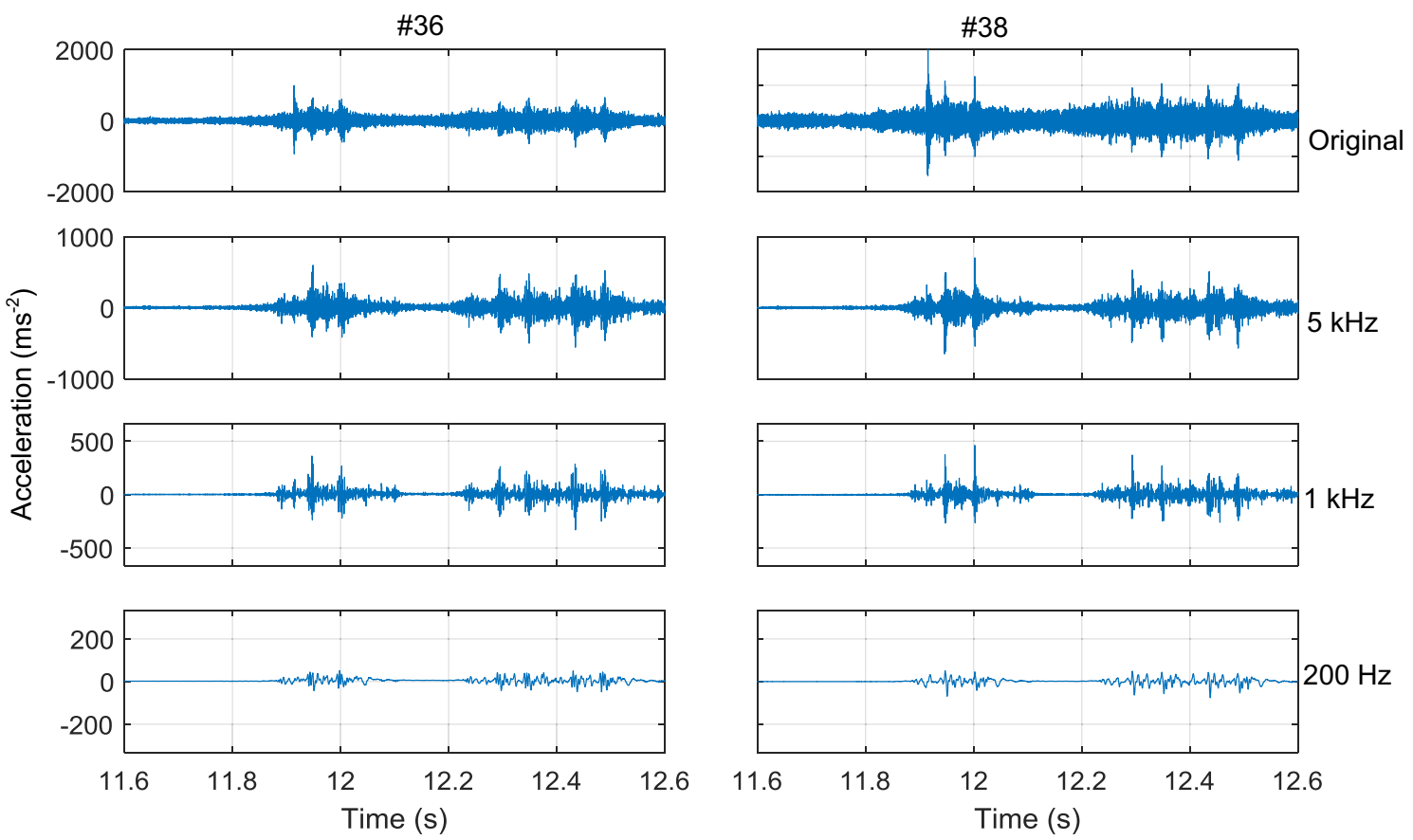

Fig. 9 Vertical acceleration with various low-pass filters, sensors 36 and 38, at $177 \mathrm{~km} / \mathrm{h}$ (facing through route) 

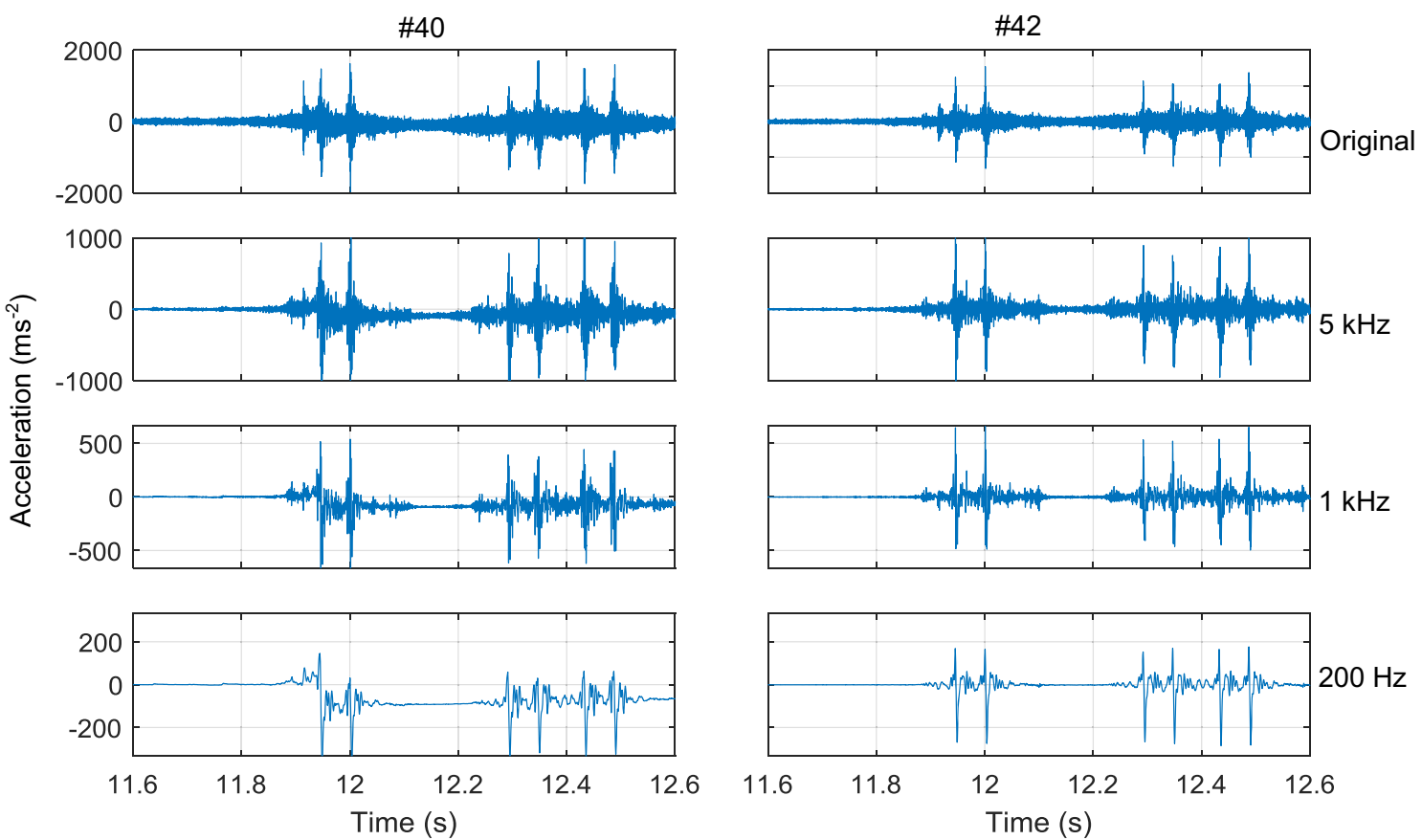

Fig. 10 Vertical acceleration with various low-pass filters, sensors 40 and 42, at $177 \mathrm{~km} / \mathrm{h}$ (facing through route)
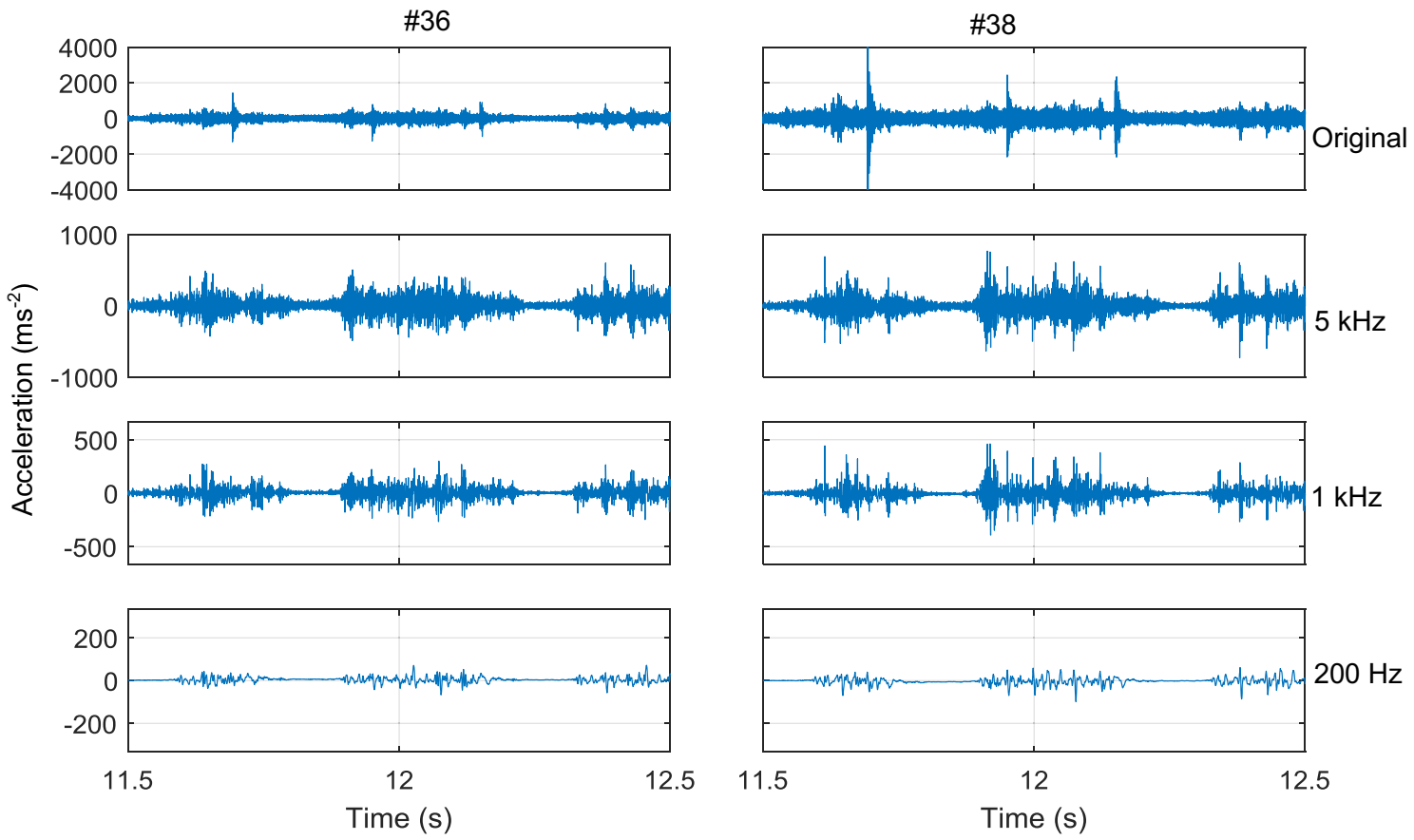

Fig. 11 Vertical acceleration with various low-pass filters, sensors 36 and 38, at $200 \mathrm{~km} / \mathrm{h}$ (facing through route)

frequency information and may then no longer be able to detect crossing damage and degradation. Furthermore, the rail acceleration is influenced significantly by the train speed and train type.
Although, reasonably, a higher acceleration is interpreted as worse, the link between acceleration and force and potential damage is too complicated to allow condition monitoring with one accelerometer. 

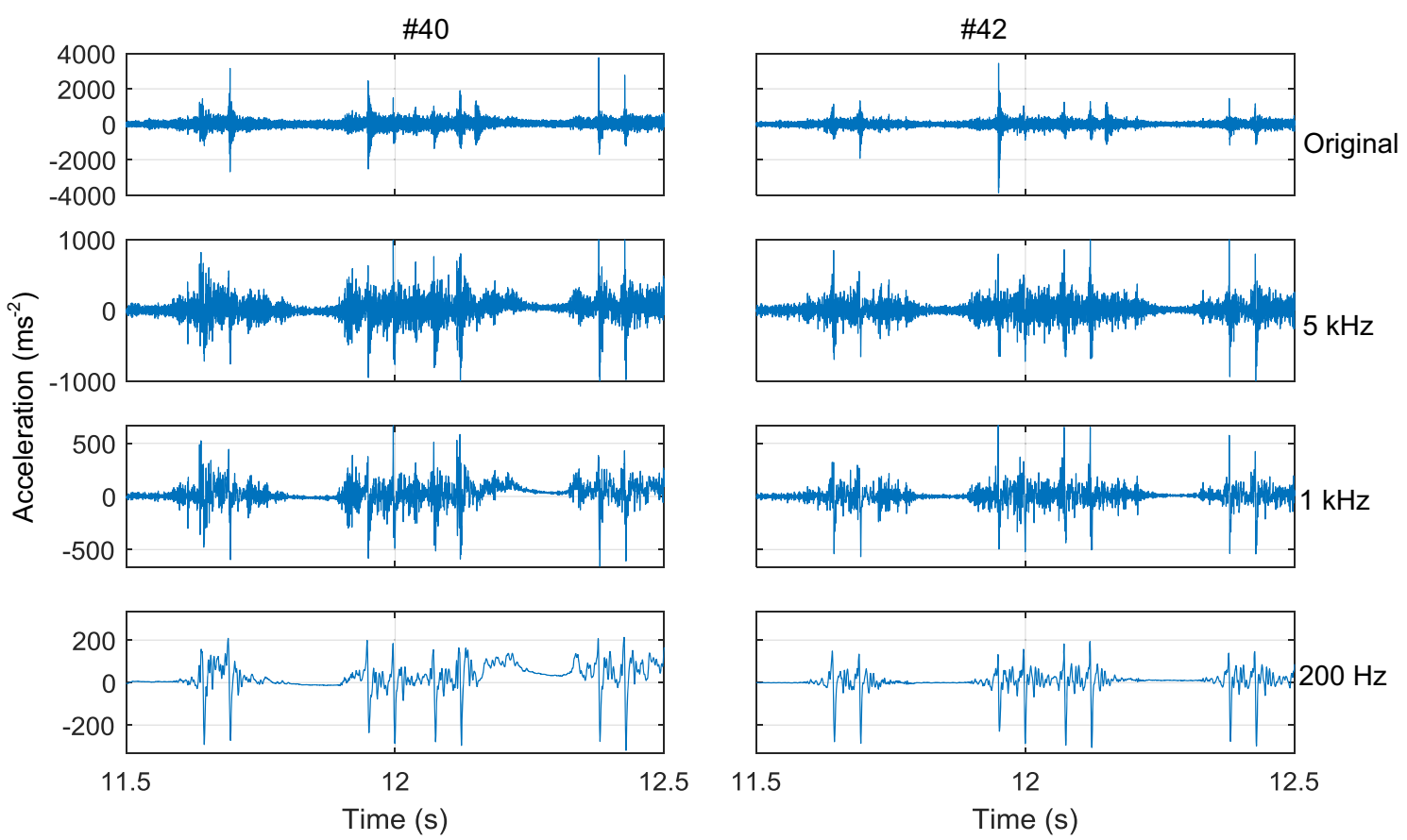

Fig. 12 Vertical acceleration with various low-pass filters, sensors 40 and 42, at $200 \mathrm{~km} / \mathrm{h}$ (facing through route)

\subsubsection{Vertical and horizontal accelerations at the crossing}

The possibility of detecting a worn crossing by comparing the vertical accelerations and the horizontal accelerations on the metalwork is described in [3]. Higher accelerations occur because of unwanted wheel flange contact at the crossing nose. A similar methodology was applied for the present trial data but instead of using the 'mean value' (the meaning of which is not clear), RMS values are used. Similar results are included for the switch data as unexpected horizontal impacts occur here when the switchblade is worn, or the switchblade position is incorrect. The RMS accelerations are computed over a window of data where the acceleration is between $10 \%$ and $100 \%$ of the peak acceleration.

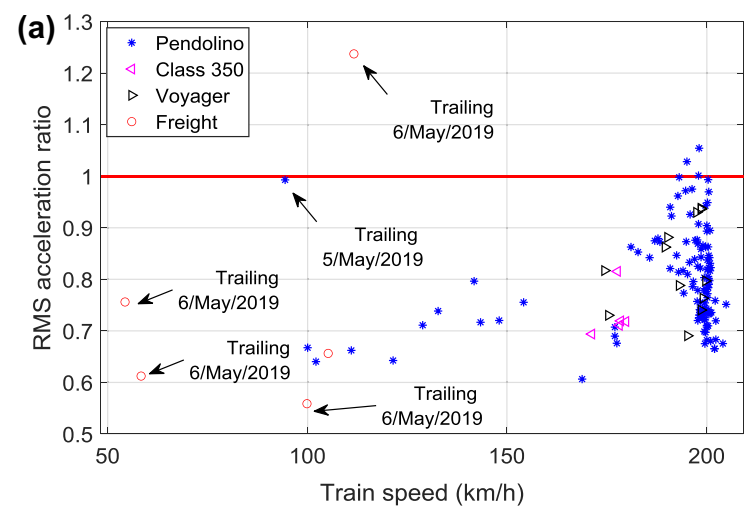

Figure 13 shows the ratio of RMS horizontal and vertical accelerations from four different train types, Pendolino, Freight, Voyager, and Class 350, with different train speeds at the S\&C. Ratios above one would be indicated as a defect [3]. Most of the cases are below one at the switch. On the other hand, a number of cases are above one at the crossing. This may imply the crossing condition is worse than that of the switch. However, the results from the crossing are unlike the results from the switch, which is more dependent on train speed. Consequently, the conclusion on condition based on this ratio may not be reliable.

The results are influenced significantly by train speed and type. Furthermore, results from the same train type and same speed within the same day show significant variation. This is due to different train conditions such as different

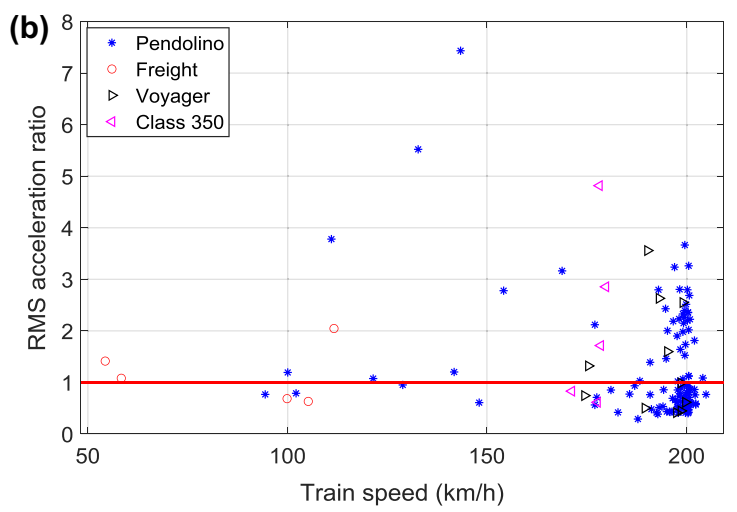

Fig. 13 Ratio of RMS horizontal to RMS vertical acceleration at a the switch and $\mathbf{b}$ the crossing for different train types and speeds 
wheel profiles. A faulty train (e.g. wheel flat) will give higher impacts at S\&C. The results are found to be influenced not only by the running speed and train type but also by the running direction. Higher 'factors' are obtained from the same speed and same train type, a Pendolino, but running in opposite directions over the switch. Unfortunately, the direction of the train is correlated with the through or diverging route for the collected data, as this is how the switch is used, so nothing can be said about whether it is the facing or trailing direction of travel that makes a difference, or the through and diverging routes.

High impacts may indicate S\&C degradation, but it can also be caused by damaged wheelsets. Therefore, as mentioned in [3], it is important to take into account where the train wheelsets are located.

\section{Strain gauge results}

\subsection{Strain results}

Three full-bridge strain gauge channels were installed for measuring the pure shear strain at either end of a $220 \mathrm{~mm}$ long section of crossing between two bearers, and the bending strain at the midpoint. The bridge configurations compensate for temperature variations and are nominally insensitive to loading in directions other than vertical. The bridge configuration also improves the signal-to-noise ratio $[5,7]$. The raw bending and shear strain data for trains travelling at 100 and $193 \mathrm{~km} / \mathrm{h}$ are shown in Fig. 14.

The shear strains are only reaching 5-10 microstrain $(\mu \varepsilon)$ which is approaching the lower limit of strain measurement. Some background noise of around $1 \mu \varepsilon$ is visible on the signals. The shear strain goes negative (positive) as the first wheelset approaches in the reverse (normal) direction, then reverses sign as each wheelset crosses over the sensor. On the slower train (left) there is an impulsive disturbance around $13.3 \mathrm{~s}$ that also appears in the bending strain.

The bending strain is largely in one direction as the train wheels pass over the crossing with a small amount of reverse direction bending as the leading wheelset of a bogie (or of two closely spaced bogies) approaches. The bending strain is nearly three times higher for the higher speed train and about 10 times larger than the shear strain. Individual wheelsets are easily identifiable, much more so than from accelerometer data. This is because strain is more like displacement than acceleration in that the amplitude tends to decrease with increasing frequency.

\subsection{Forces calculation (from shear strain difference)}

The forces are estimated from two separate shear strain full-bridge channels by

$F=2 \alpha \gamma_{\mathrm{A}}-2 \beta \gamma_{\mathrm{B}}$,

where $\gamma_{\mathrm{A}}$ and $\gamma_{\mathrm{B}}$ are the pure shear strain at $\mathrm{A}-\mathrm{A}^{\prime}$ and $\mathrm{B}-\mathrm{B}^{\prime}$ cross sections, respectively, as shown in Fig. 3; constants $\alpha$ and $\beta$ depend on the material properties and the crosssectional geometry:

$\alpha=\frac{I_{\mathrm{A}} t_{\mathrm{A}} G}{Q_{\mathrm{A}}}$,

$\beta=\frac{I_{\mathrm{B}} t_{\mathrm{B}} G}{Q_{\mathrm{B}}}$,

where $I_{\mathrm{A}}$ and $I_{\mathrm{B}}$ are, respectively, the moments of inertia at cross sections $\mathrm{A}-\mathrm{A}^{\prime}$ and $\mathrm{B}-\mathrm{B}^{\prime}$ computed about the neutral axis, $G$ is the shear modulus of the crossing material, $t_{\mathrm{A}}$ and $t_{\mathrm{B}}$ are the width of the member cross-sectional area at the sensor locations, and $Q_{\mathrm{A}}$ and $Q_{\mathrm{B}}$ are the first moments of (a)
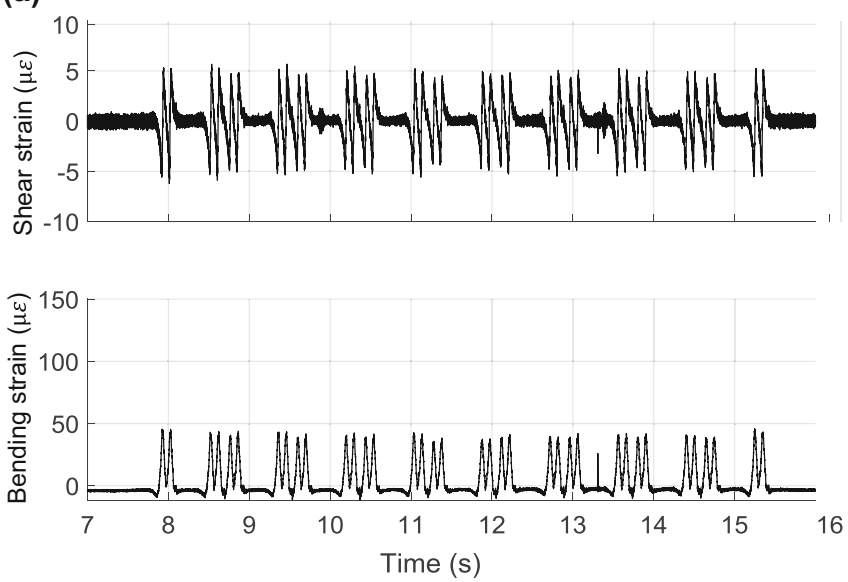

(b)
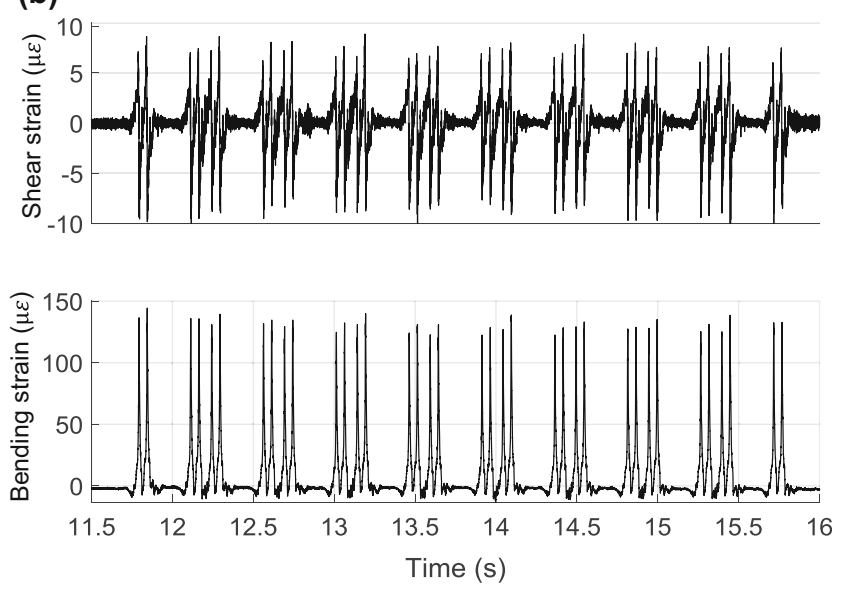

Fig. 14 Strain results from passenger train with different speeds: a $100 \mathrm{~km} / \mathrm{h}$ (trailing diverging route); b $193 \mathrm{~km} / \mathrm{h}$ (facing through route) 
area at cross sections $\mathrm{A}-\mathrm{A}^{\prime}$ and $\mathrm{B}-\mathrm{B}^{\prime}$, respectively, with consideration of the area above the neutral axis.

\subsection{Frequency analysis}

To identify the required frequency range for bending strain and the forces, one-third octave band spectrum for three train datasets is shown in Fig. 15.

One-third octave spectra from the same train types but with different speeds and different train conditions are compared in Fig. 15. Figure 15a shows the results from the bending strain. The energy from lower speed is mostly below $20 \mathrm{~Hz}$ but from a high-speed train is mostly below $300 \mathrm{~Hz}$. Figure 15b shows the spectrum for the force. Significant energy found above $2 \mathrm{kHz}$ was traced to interference from the traction return current of electrically powered trains. In general, the peak forces from the higher speed trains are higher than those from lower speed ones.

The peak force is dominated by the higher frequency for higher speed trains and a lower frequency for lower speed trains. Ignoring the electrical interference, the force distribution from lower- and high-speed trains is below $2 \mathrm{kHz}$. The energy is mainly located at lower frequencies for the lower speed trains.

A similar pattern is found comparing the results from trains with and without wheelset problems, as shown in Fig. 15b. High forces can be found from 10 to $300 \mathrm{~Hz}$ and $500-2,000 \mathrm{~Hz}$, which represents frequency range for the P2 force (low-frequency impact forces) and P1 force (transient high-frequency impact forces), for results from higher speeds, as shown in Fig. 15b. The first impact peak, P1, occurs when the wheel transfers from the wing rail to the crossing, a major contributor to the crossing surface degradation, and the second peak, $\mathrm{P} 2$, occurs following the first peak, the dominant cause of foundation degradation [26].

The bending strain amplitude from the normal and faulty train is similar but higher forces can be found from the faulty train at higher frequencies. Furthermore, the same peak can be found in the bending strain spectrum at lower frequencies, but no peaks can be found in the higher frequencies, as shown in Fig. 15a. In summary, to capture the bending strain and forces appropriately, $300 \mathrm{~Hz}$ and $2,000 \mathrm{~Hz}$ bandwidths are required, respectively. Furthermore, bending stain only captures low-frequency information such as P2 forces but cannot capture the highfrequency content such as P1.

\subsection{Measured forces}

Including frequencies up to $2,000 \mathrm{~Hz}$ is suggested for the force results at the crossing to capture P1 and P2 forces. The measured force should correlate with crossing damage such as cracks, rolling contact fatigue (RCF) and plastic deformation. A wheel load detector for measuring the wheel loads of passing trains has been commercially available and used in the UK to detect damaging trains and to get these trains removed from the track as soon as possible. However, consideration of dynamic loading is usually neglected and the actual impact force, which is one of the most crucial factors for material degradation, cannot be captured. Therefore, it is very important to try to measure dynamic forces, a conclusion reached in other works [26, 27]. The results from train speeds 53, 105 and $193 \mathrm{~km} / \mathrm{h}$ in the trailing and facing directions are discussed first, and the average results from all trains are shown in the end to show the importance of consideration of the dynamic effect.
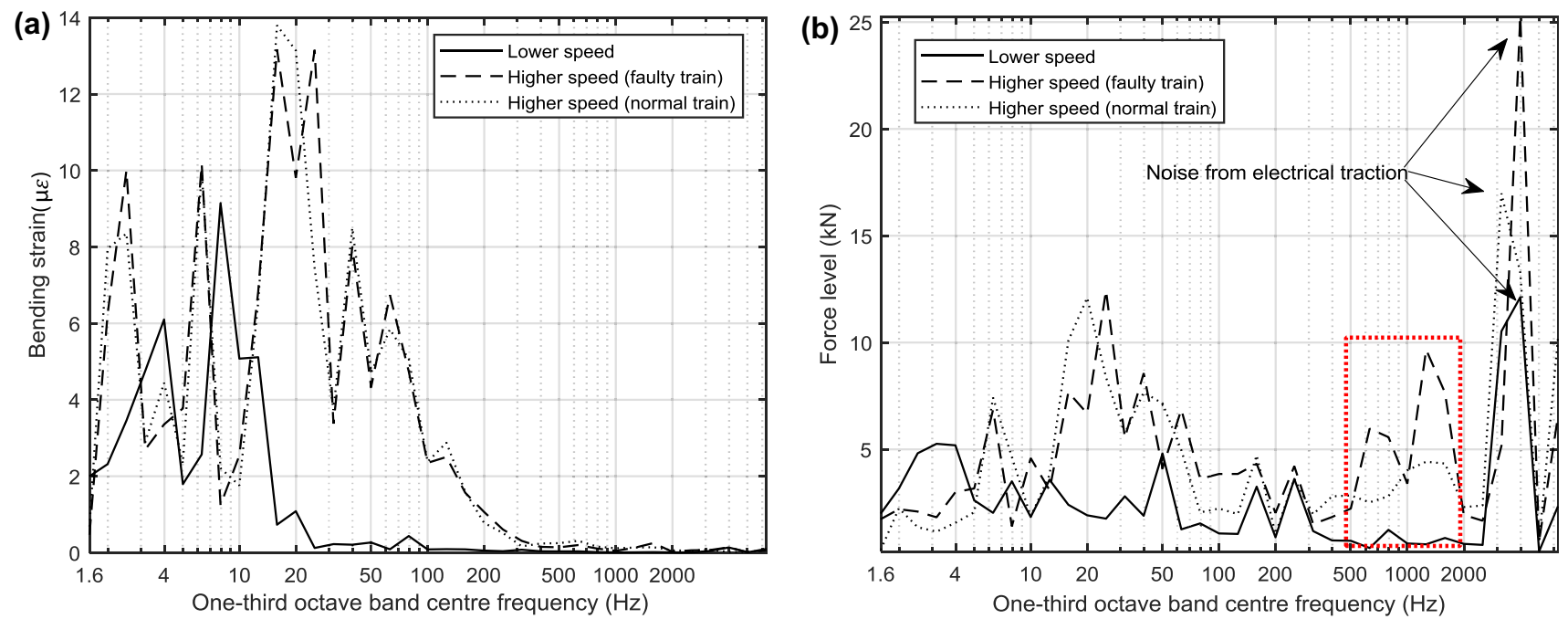

Fig. 15 One-third octave band energy spectrum of $\mathbf{a}$ bending strain and $\mathbf{b}$ the forces 


\subsubsection{Results from the trailing direction}

Figure 16 shows the shear strain results at the $\mathrm{A}-\mathrm{A}^{\prime}$ and $\mathrm{B}-$ $B^{\prime}$ cross sections for four axles from a $53 \mathrm{~km} / \mathrm{h}$ train travelling in the trailing direction. The force within the measuring region between $\mathrm{A}$ and $\mathrm{B}$ based on known cross section and material data and shear difference is shown in the second graph. The full-bandwidth vertical acceleration on one side of the crossing between A and B is shown in the third graph. The difference between left and right crossing vertical acceleration, which tends to have high potential for detecting the load transfer location, is shown at the bottom, low pass filtered to $500 \mathrm{~Hz}$.

Shear strain results from the $\mathrm{A}-\mathrm{A}^{\prime}$ cross section are similar to those from cross section $\mathrm{B}-\mathrm{B}^{\prime}$ but with a temporal shift equal to the time taken for a wheelset to travel from $\mathrm{A}$ to $\mathrm{B}$, at least for the first two wheelsets indicated at ' 1 ' and ' 2 '.

Based on the vertical acceleration and the difference between left and right accelerations, the load transfers for the second pair of wheelsets occur at positions marked ' 7 ' and ' 8 ', around $440 \mathrm{~mm}$ after the wheelset passes over A-B. A similarly positioned load transfer for the leading wheelsets is indicated by ' 5 ', and ' 6 '. Considering the results are from the trailing direction, the loads transfer from the crossing nose to the wing rail. As shown in Fig. 16, the first wheelsets tend to transfer the load after the measure section, and the second wheelsets tend to transfer the load to the wing rail before the measured section. Therefore, forces cannot be measured for the second wheelsets because the load is applied at the wing rail instead of the crossing nose where the strain gauge is installed.

Figure 17 shows similar data for a $105 \mathrm{~km} / \mathrm{h}$ train moving over the crossing in the trailing direction. In this

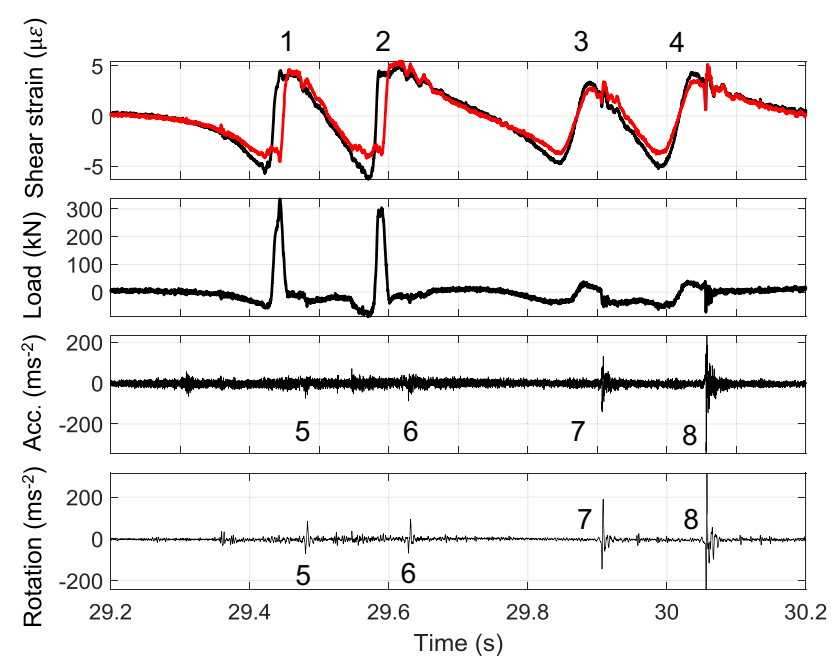

Fig. 16 Trailing $53 \mathrm{~km} / \mathrm{h}$ train

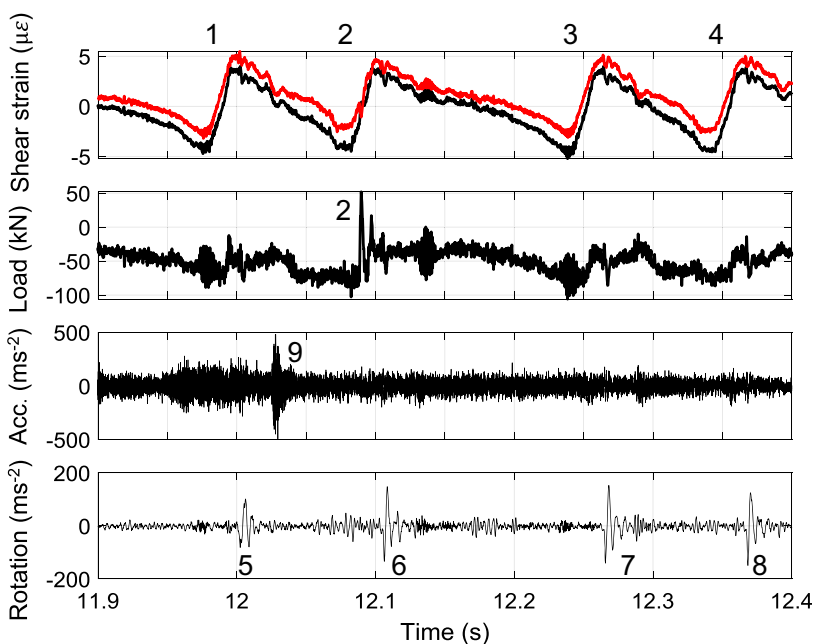

Fig. 17 Trailing $105 \mathrm{~km} / \mathrm{h}$ train

case, the shear strains are similar to those from the $53 \mathrm{~km} / \mathrm{h}$ freight train and only one oscillatory force appears with a reasonable value. Again, the load transfer, as indicated by ' 5 '-' 8 ' in the crossing rotation disturbance at the bottom of the figure, happens outside of the load measuring region. This time, the load transfer occurs about $200 \mathrm{~mm}$ closer to the crossing nose than the instrumented section. The acceleration signal is notable for being significantly more variable than from the freight train with an odd excitation marked as ' 9 ' in the figure. The wheelsets of the train may be somewhat rough and potentially there is a wheel flat at the peak acceleration. Acceleration does not show much at the time of load transfer but the rotation signal low pass filtered at $500 \mathrm{~Hz}$ shows the load transfer well and with some consistency.

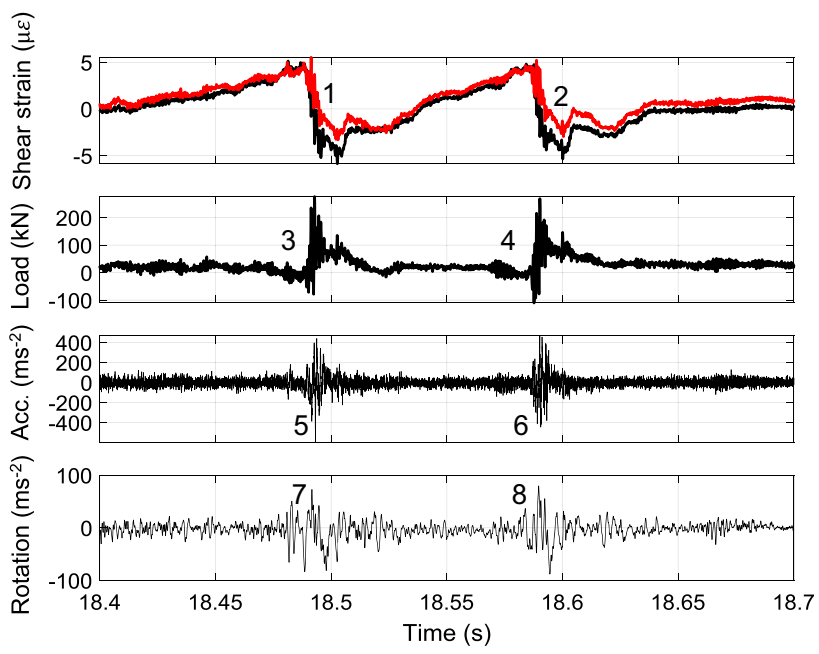

Fig. 18 Facing $105 \mathrm{~km} / \mathrm{h}$ train 


\subsubsection{Results from the facing direction}

Figure 18 shows the acceleration and shear strain data for two wheelsets on a $105 \mathrm{~km} / \mathrm{h}$ train travelling in the facing direction. The shear strains are the opposite way up because of the direction of train travel. The marks ' 1 ' and ' 2 ' show where two wheelsets on one bogie pass over the instrumented section. The load transfer location can be observed from the forces (marks ' 3 ' and '4'), vertical accelerations (marks ' 5 ' and ' 6 '), and the difference between left and right vertical acceleration (marks ' 7 ' and ' 8 '). For the force results, a higher peak (P1 force) occurs first when the load transfer happens and a second peak (P2 force), which is lower and wider than the first peak, occurs following the first peak.

Figure 19 shows the acceleration and shear strain data for two wheelsets on a $193 \mathrm{~km} / \mathrm{h}$ train travelling in the facing direction. Similar strain results (1 and 2) are obtained compared to the lower speed results, but an extra upward peak appears in the shear strains, marked with ' 3 ' around $13.8 \mathrm{~s}$ between the two wheelsets. This may be due to the torsion effect. However, this effect cancels after subtracting the two results for calculating the forces. The force shows some general positive change but mainly oscillation. The peak values appear to be reasonable for the vehicle type, but it is evidently affected by vibration in the measuring section that makes the interpretation as load suspect. The difference between left and right vertical acceleration (5 and 6) shows some evidence of load transfer. Based on additional wheelsets and the results from other similar speed trains, the load transfer is sometimes clear but often messy around $193 \mathrm{~km} / \mathrm{h}$. The accelerations show some spikes that could correspond to load transfer positions but there is also an additional acceleration burst marked with '4'.

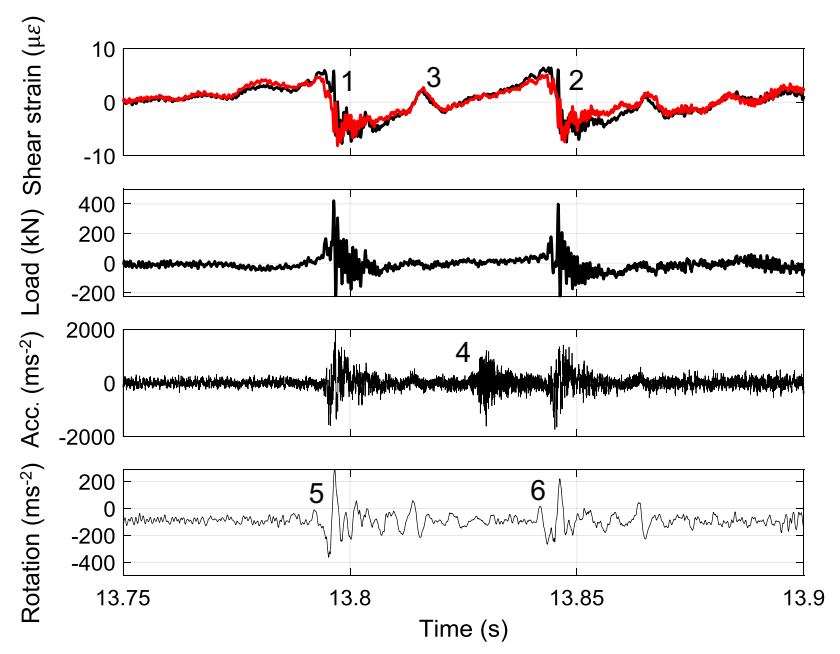

Fig. 19 Facing $193 \mathrm{~km} / \mathrm{h}$ train

\subsubsection{Average results from all trains}

Figure 20 shows the average of the maximum forces from each train after low-pass filtering with cut-off frequencies of $100 \mathrm{~Hz}, 1$ and $2 \mathrm{kHz}$. The UK wheel load limit for plain track [28] is also indicated with imposed speed limits. Based on UK standards, a speed restriction needs to be applied when the measured force is within the warning range. As shown, without consideration of dynamic effects, the forces are underestimated and only results with $100 \mathrm{~Hz}$ low-pass filter are within the allowable region. Much higher dynamic forces are obtained at the crossing compared to the results measured at the plain track where the wheel load is typically measured. These measurements are generally measured with bending strain rather than shear strain and naturally show lower frequency behaviour, as seen in the third-octave results above.

This may be the reason why crossing service life is often shorter than the design service life-it suffers significantly higher impact forces than the forces measured on plain track and the dynamic effect is usually ignored. Furthermore, the crossing degrades significantly faster after a fault develops. For example, a degraded crossing with $24 \mathrm{mrad}$ crossing dip angle causes around three times larger impact forces than a crossing with zero dip angle [29]. Therefore, consideration of dynamic forces is very important and the bandwidth over which the force is measured is critical.

\subsection{Comparison of peaks in dynamic force and vertical rail acceleration}

Attaching an accelerometer to the rail or crossing is a more attractive proposition than using strain gauges. However, unlike force, which can correlate with crossing degradation, it is difficult to use acceleration as an indicator of $\mathrm{S} \& \mathrm{C}$ degradation. Peak rail vertical accelerations and

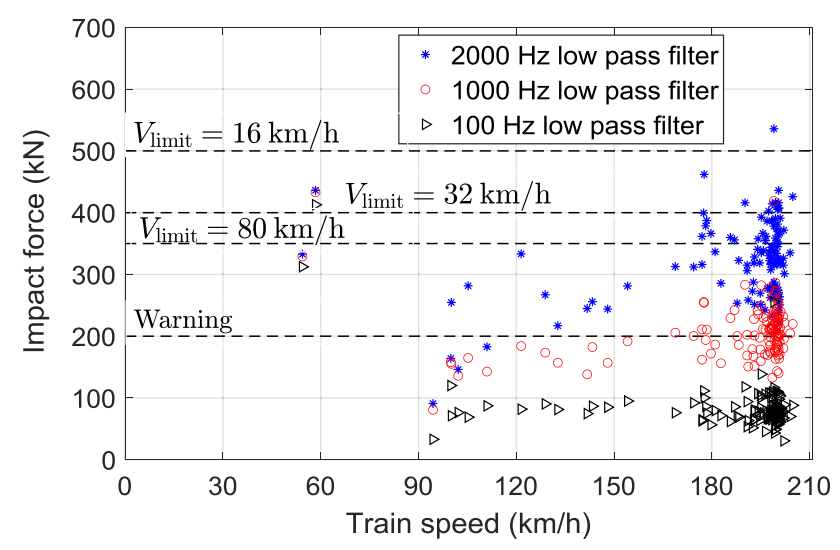

Fig. 20 Crossing forces with various low-pass filters 
impact forces at the crossing load transfer point are compared and assessed. Results from four trains are discussed, shown in Figs. 21-24. Based on the conclusions from Sect. 4.2, a $2 \mathrm{kHz}$ low-pass filter is applied to accelerations. On the other hand, although $2 \mathrm{kHz}$ has shown capability for capturing dynamic characteristics for the impact forces, at least $10 \mathrm{kHz}$ is required for the rail accelerations to identify a faulty train [22]. Therefore, lowpass filters with upper cut-off frequencies of $2 \mathrm{kHz}$ and $10 \mathrm{kHz}$ are both used for rail accelerations to see which has the higher correlation with estimated dynamic force.

Figure 21 shows the results from a $100 \mathrm{~km} / \mathrm{h}$ passenger train. The force exceeds $200 \mathrm{kN}$ about 8 times. The most severe peak forces are associated with a small subset of all the wheelsets. There appears to be no reason for the spread of dynamic load results across different wheelsets other than the stochastic nature seen previously in the forces from different wheelsets. Meanwhile, only one strong peak is seen in the rail vertical accelerations even with a $10 \mathrm{kHz}$ low-pass filter and it happens outside of the sensor location. After filtering at $2 \mathrm{kHz}$, the acceleration does not show any particularly strong peaks. The correlation between the force and acceleration is poor. This agrees with the previous comparisons over a few wheelsets.

Figure 22 shows the results from a passenger train travelling at $193 \mathrm{~km} / \mathrm{h}$. In this example, the force peaks of some magnitude are found for every wheelset, accompanied by strong acceleration peaks. Larger dynamic forces align with higher accelerations and the same trend is found for results after 2 and $10 \mathrm{kHz}$ low-pass filtering. Unlike the results from the lower-speed train, where only positive impact forces are seen, negative impact forces are seen with almost the same magnitude as the positive impact
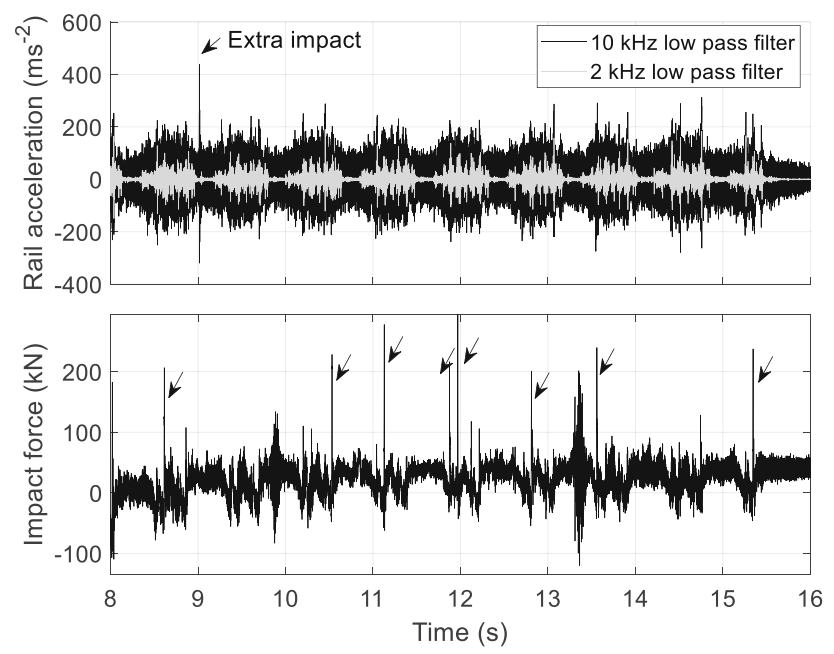

Fig. 21 Comparison of rail vertical accelerations and impact forces for $100 \mathrm{~km} / \mathrm{h}$ passenger train (trailing diverging route)
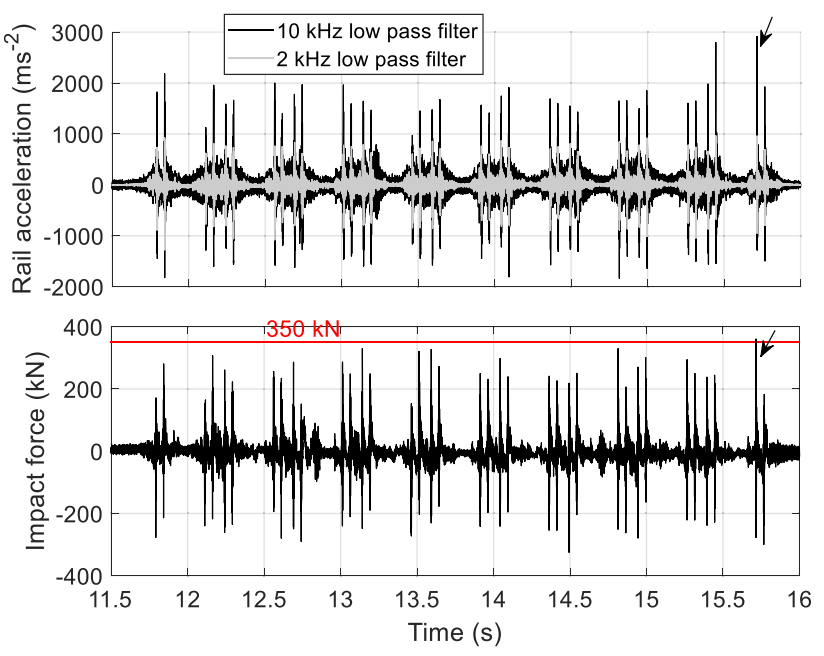

Fig. 22 Comparison of rail vertical accelerations and impact forces for normal passenger train with higher speed $(V=193 \mathrm{~km} / \mathrm{h}$ ) (facing through route)
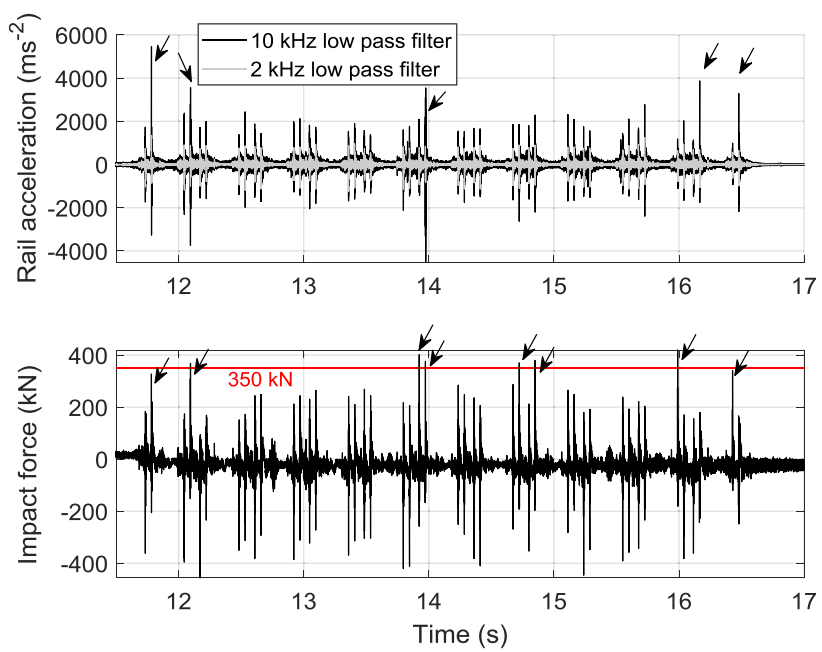

Fig. 23 Comparison of rail vertical accelerations and impact forces for faulty passenger train with higher speed $(V=193 \mathrm{~km} / \mathrm{h}$ ) (facing through route)

forces. This suggests that the dynamic force is associated with vibration in the structure of the crossing rather than simply dynamic load from the wheelset above.

Figure 23 shows the results from the same train type as in Fig. 22 and the same train speed but perhaps with more worn wheelsets. Higher accelerations are obtained compared to the results from a normal passenger train and some strong peaks can be found in the accelerations due to defective wheelset(s). However, although clear peaks can still be found for both data, the acceleration results no longer follow the impact force trend. Some high-impact forces do not have corresponding high accelerations. The rail accelerations are interspersed with a number of unexpected impacts probably linked to the defective 


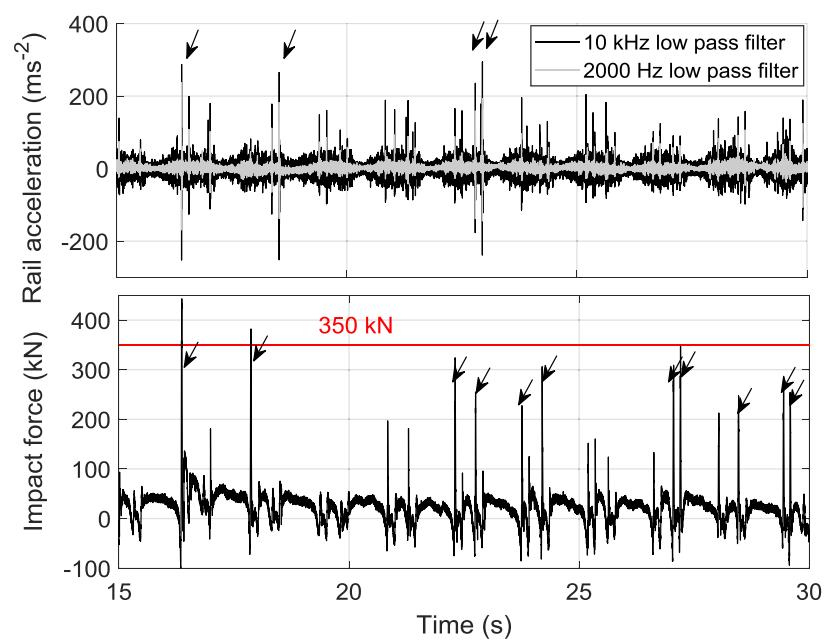

Fig. 24 Comparison of rail vertical accelerations and impact forces for freight train $(V=55 \mathrm{~km} / \mathrm{h})$ (trailing diverging route)

wheelset(s) and make it difficult to obtain useful conclusions for monitoring the crossing. Although a low-pass filter can remove these impacts, the remaining data loses potentially important impacts and so is not able to capture the most significant dynamic forces.

Figure 24 shows the results for a freight train travelling at $55 \mathrm{~km} / \mathrm{h}$. Similar phenomena are found compared to the lower speed passenger train, as shown in Fig. 21. However, although the maximum accelerations for both cases are similar, around $200 \mathrm{~m} / \mathrm{s}^{2}$, the force results are significantly different. The forces for the lower speed passenger train are around $200 \mathrm{kN}$ but the results from the freight train exceed $400 \mathrm{kN}$. Therefore, correlation between rail accelerations and the forces seems to be poor-the load may indicate more damage from the freight train than a similar-speed passenger train, whereas the acceleration does not distinguish between them.

\subsection{Proposed condition monitoring for crossing degradation}

A possible index for monitoring crossing degradation can be obtained by considering the shake-down map [30] with normalized vertical forces determined from the estimated the forces and the adhesion utilization, as shown in Fig. 25. $\mathrm{RCF}$ cracks start to initiate when the value is within the 'ratchetting' area. Therefore, the proposed index can be directly correlated to low-cycle fatigue failure.

Figure 25 shows how the estimated load data are mapped onto a shakedown diagram. Note that only the load applies between the instrumented section, which can happen when the load transfers from wing rail to crossing for the facing direction or when the load before transferring to the wing rail in the trailing direction, is considered. The

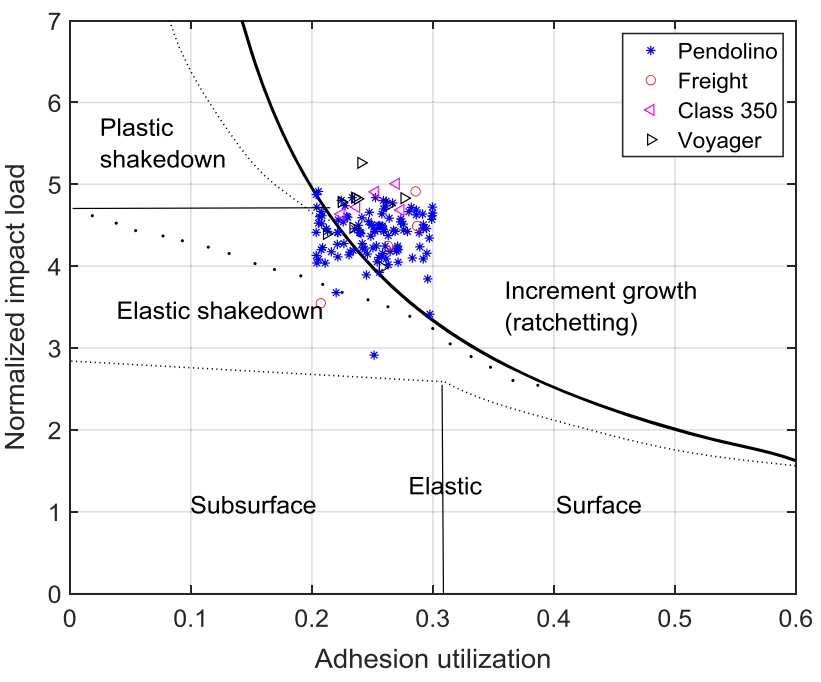

Fig. 25 Potential condition monitoring approach for crossing degradation

vertical axis shows the normalized forces that are obtained from the estimated forces and the geometry of the wheel and the crossing nose at the measured location. The horizontal axis shows the adhesion utilization, the magnitude of the sum of tangential forces relative to the normal force. It is bound by the friction coefficient. The measured data are mapped considering a friction coefficient of 0.3 (typical for dry rails) and assuming that the slip ratio is randomly distributed between $70 \%$ and $100 \%$. This assumption is motivated considering the fact that, in the crossing region, high tangential forces are needed to guide the wheelset through, thus high slip ratios are expected.

As shown in Fig. 25, most working points for the instrumented crossing falls within the ratcheting area of the shakedown map indicating a high risk of fatigue failure. In fact, defect on the crossing was found from a site inspection, as shown in Fig. 26. A 3D scan was carried out and the crossing dip angle was found to be around $24 \mathrm{mrad}$, which is considered to be a poor condition and causes three times higher impact forces compared to the nominal crossing geometry [29].

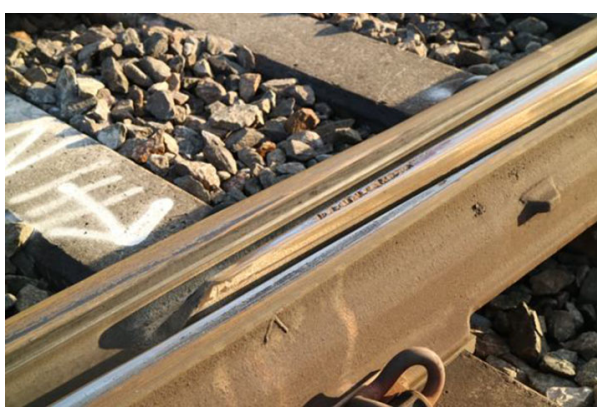

Fig. 26 Site inspection for the crossing 
The proposed condition monitoring approach uses the estimated forces, which are ideally the actual forces applied to the crossing, to predict the crack initiation. There is no need to identifying the train because the approach takes into account a variety of impact forces induced by different train speeds and different train types with different wheel conditions. The index can directly correlate to crossing crack initiation and can apply to all crossings irrespective of angle with the known material properties and cross section parameter [see Eqs. (1-3)]. Indication of crack initiation can be identified and used for predictive maintenance. Furthermore, the crossing condition can be identified directly with the same warning baseline (threshold) for different support conditions.

Unfortunately, the load measured from the shear strain gauge arrangement is limited to load applied between the measurement positions, is a small value, is subject to errors in gauge position and cannot be applied too close to bearers. This makes the method practically difficult.

\section{Data correlation analysis}

Figure 27 shows the correlations between peak force (after 2,000 Hz low-pass filtering), train speed, maximum vertical acceleration on the rail, and maximum acceleration on the bearer (derived from the geophone data), at the same location.
The bearer vertical maximum accelerations are highly correlated with train speed. Vertical crossing acceleration falls into two regions, one where the acceleration increases modestly with train speed followed by a wide range of acceleration with larger values for the highest train speeds. This leads to a low correlation at 0.33. A low correlation factor of 0.2 is obtained between rail acceleration and the force. This may be partly because of extra impulsive loads detected from near the crossing, or simply because the correlation is genuinely low. A correlation factor 0.6 is obtained between bearer acceleration and impact forces, which is still rather low. Furthermore, correlation between rail and bearer acceleration is low, at 0.33 , and this is expected as the accelerometer on the bearer misses highfrequency content seen in the crossing. Therefore, the accelerations on the bearer are not able to capture the high impact on the crossing and consequently it is not suitable for monitoring the crossing degradation, at least in terms of the forces.

Figure 28 shows the correlation between bending stress, the force and bearer displacement. High correlation is found between bearer displacement and bending stress. Therefore, there might be potential for using bending strain for monitoring track support condition, but the relationship between the observed bending and the forces depends on the uncertain track support, whereas the shear strain method is directly related to force although the support still affects the force. On the other hand, lower correlation is obtained between both impact forces and bending stress

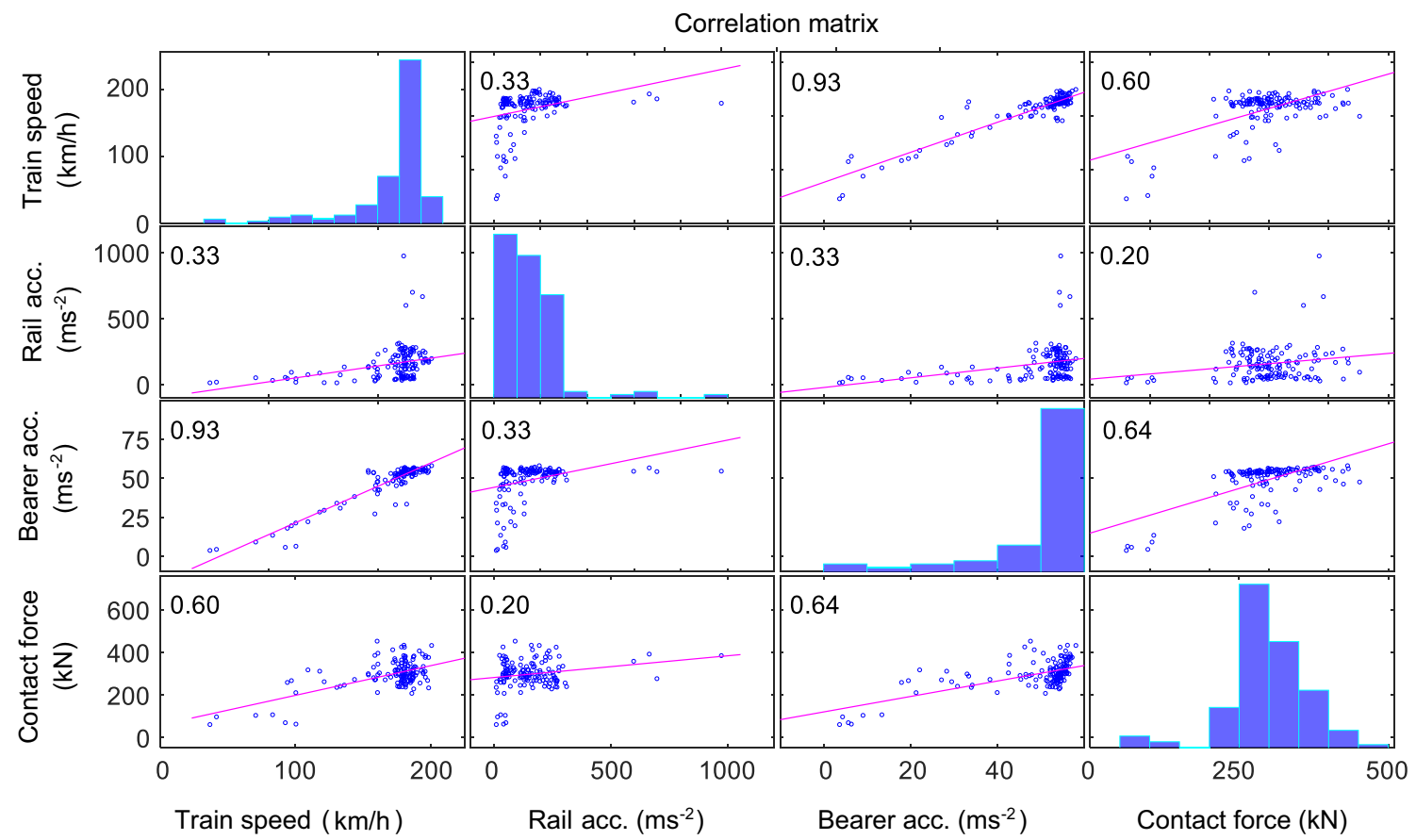

Fig. 27 Correlations between train speed, vertical rail (crossing) acceleration, bearer acceleration and impact forces 


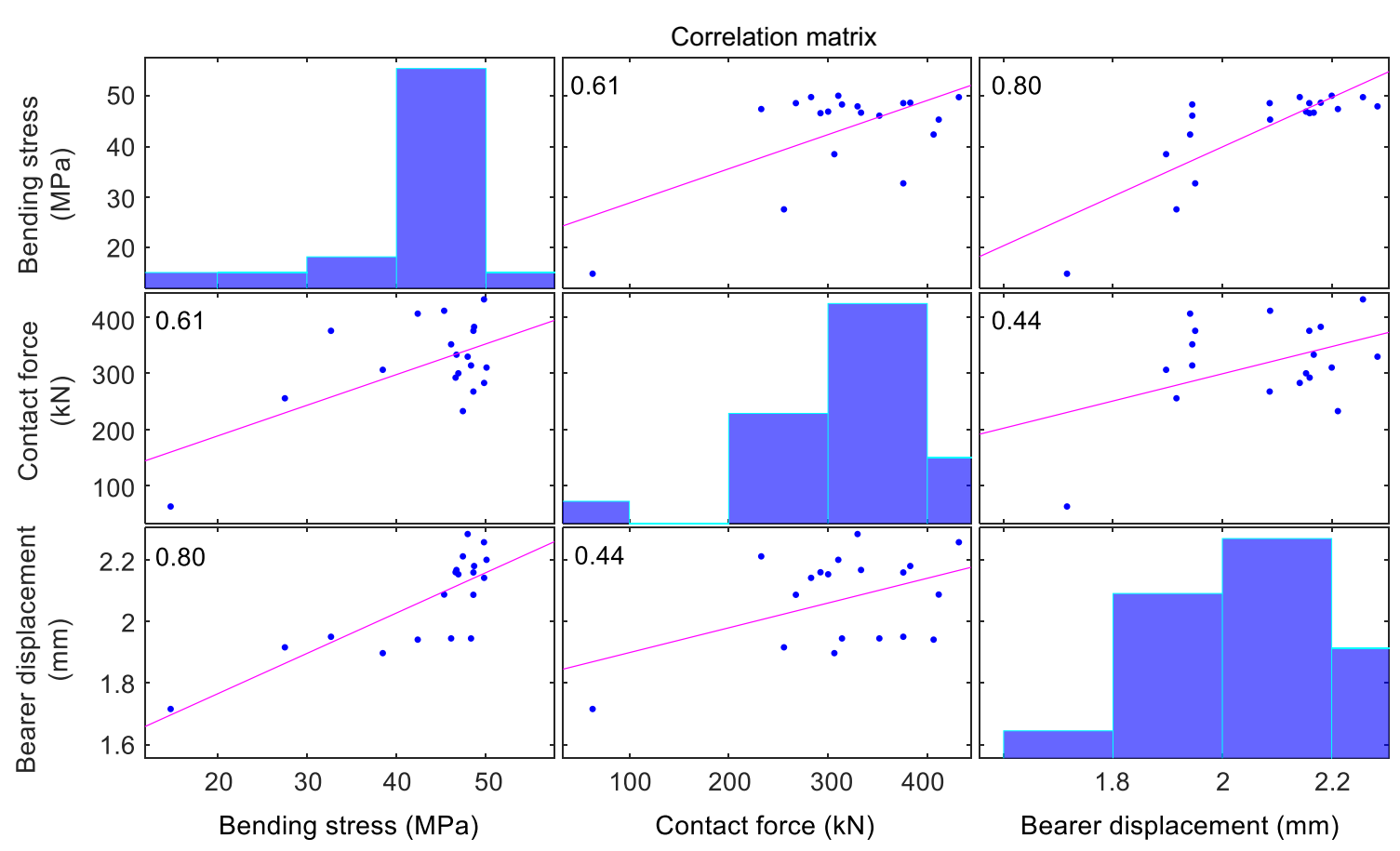

Fig. 28 Correlations between bending stress, contact forces and bearer displacement

and impact force and bearer displacement. Results for bending stress (below $300 \mathrm{~Hz}$ ) and bearer displacement (also below $300 \mathrm{~Hz}$ ) both belong to relatively low-frequency content compared to impact forces in a higher frequency range, so cannot be used for monitoring degradation due to high dynamic loading.

\section{Conclusion}

Measurement data collected from accelerometers and geophones mounted variously on the rail, crossing and bearers at various locations around a switch and crossing on the UK rail network have been analysed and discussed with regard to potential application to condition monitoring of railway switches and crossings, in particular associated with degradation of the crossing by high dynamic loads. Data collected at the same time from strain gauge bridges near the load transfer point of the crossing have been discussed and comparisons made between the use of accelerometers and strain gauges. An attempt has been made to estimate dynamic forces at the transition from wing rail to crossing nose, and vice versa.

Some conclusions in terms of data acquisition:

- At least $10 \mathrm{kHz}$ bandwidth and $5,000 \mathrm{~ms}^{-2}$ measurement range is required for rail accelerations. $20 \mathrm{kHz}$ is required for high-speed trains if the impacts from wheel irregularity are to be identified.
- A $2 \mathrm{kHz}$ bandwidth is required for measuring pure shear strain at the crossing to capture P1 and P2 forces. On the other hand, $300 \mathrm{~Hz}$ is enough for measuring bending strain at the crossing. Unlike accelerometers that require wide ranges to avoid saturation, strain gauges already naturally have the required range but are more fragile than accelerometers.

In terms of sensor locations:

- Bearer results from two sides at the switch have shown significant differences, especially results close to the POE. This may not be typical but is an important consideration if a single sensor solution is sought. There is a potential for twist faults to develop at the switch that a single sensor cannot identify.

- Rail accelerations at the most crucial location at the crossing compared with the results around $1 \mathrm{~m}$ away show that the results from these two locations are not similar except for the lowest speed trains. Unfortunately, placing an accelerometer right next to the crossing load transfer region requires the widest acceleration range and best mounting technique for long-term monitoring to be possible.

- Sensors on the bearers and bending strain on the crossing do not capture large dynamic loads at higher frequencies. Therefore, they cannot be used for monitoring $\mathrm{S} \& \mathrm{C}$ faults associated with high dynamic loads.

In terms of potential data characteristics for $\mathrm{S} \& \mathrm{C}$ condition monitoring: 
- Geophones on the bearer are already known to have potential for monitoring track support conditions with peak-to-peak displacement used as a condition monitoring quantity. Correlation between bearer displacement and bending strain on the rail is high. Therefore, there is also potential using bending strain for monitoring track support condition. Furthermore, bending strain has shown capability for capturing P2 force, which is crucial index for ballast degradation.

- Rail or crossing accelerations are so variable that their use for monitoring the condition of $\mathrm{S} \& \mathrm{C}$ seems unlikely to be effective. The accelerations are influenced significantly by train speed, train type, train direction, and train wheelset condition and also pick up accelerations from wheelsets passing over nearby joints or a wheelset hitting the crossing nose or other similar events. It may be possible to use the wheelset position if available so that accelerations directly relating to the crossing or other specific location of interest can be separated out. While a $1 \mathrm{kHz}$ low-pass filter can remove some acceleration coming from elsewhere, the results are no longer able to capture the crucial dynamic information at the crossing. There is also a requirement that the accelerance from all point on the track to the accelerometer location remains essentially constant. Over the switch lifetime this is unlikely to be the case.

- Very low correlation has been found between rail accelerations and impact forces that are more relevant to crossing degradation related to the formation of cracks. Furthermore, rail acceleration is not suggested for monitoring support stiffness due to poor performance at lower frequencies unless the system is designed only for high-speed trains.

- Dynamic force derived from the design strain gauge configuration has shown the potential for monitoring crossing condition. A monitoring index has been proposed based on the impact force results and has shown capability for identifying the crossing condition directly. The method takes into account the effect of faulty trains, train speed, and train types and has shown consistency with the site inspection results. The proposed method can be adopted for any turnout type and can be used for a varying range of traffic. Furthermore, the same warning baseline can be used for different sites and the measured results can be directly adopted.

- Although the strain gauge results are promising, results from higher speed train are confusing because of oscillations induced into the crossing by the high forces. Further study is needed to understand the limitations of the dynamic force estimation, for example different sensor installation location, strain gauge configuration, or strain gauge type [18, 31-33]. The monitoring index based on the shakedown theory is promising, but the friction coefficient used in the present work varies with environmental conditions. Consideration of measuring the actual tangential forces can provide more realistic results and improve the existing design system. Furthermore, the dynamic force estimation relies on an accurate component geometry and accurate sensor installation in terms of position on the crossing. A further study is required to quantify the sensitivity of sensor installation position errors and uncertainty in the crossing geometry as cast crossings are not necessarily exactly as their drawings particularly on their undersides.

In summary, potential of single-sensor solution for track-based condition monitoring for S\&C is low. Different sensors at different locations have different potential for capturing different $\mathrm{S} \& \mathrm{C}$ faults. Accelerometers on the rail have found more difficult for monitoring both high impact and foundation degradation. Displacement results obtained from geophones on bearers have found good potential for monitoring foundation degradation. Strain gauge results have shown good potential for monitoring crossing degradation. Further research focussing on low-frequency displacement results and high-frequency impact force results and monitoring index will be carried out in the future.

Acknowledgements Financial support has come from the Smart S\&C project, Innovate UK Grant Agreement 104427 AIR5, and the Track2Future project, EPRSC Grant Agreement No. EP/M025276/1. The authors also acknowledge the help provided by project partners Network Rail and Smart Component Technologies Ltd. In addition, Progress Rail provided the crossing geometry. Mr Louis Saadé helped with the data collection and Mr Adnan Zentani helped with the laboratory testing and equipment preparation. Finally, invaluable discussions about rail fatigue damage were had with Dr Matin Sh. Sichani.

\section{References}

1. Capacity for rail (C4R) (2015) Operational failure modes of switch and crossing, Deliverable D13.1, EU project SCP3-GA2013-605650. http://www.capacity4rail.eu/results. Accessed 21 Dec 2021

2. Shih J, Hemida H, Stewart E, Roberts C (2018) Understanding the impact of train run-throughs on railway switches using finite element analysis. Proc Inst Mech Eng Part F J Rail Rapid 233(4):359-369

3. Liu X, Markine VL, Wang H, Shevtsov IY (2018) Experimental tools for railway crossing condition monitoring (crossing condition monitoring tools). Measurement 129:424-435

4. Ma Y, Mashal AA, Markine VL (2018) Modelling and experimental validation of dynamic impact in 1:9 railway crossing panel. Tribol Int 118:208-226 
5. Boogaard MA, Li Z, Dollevoet RPBJ (2018) In situ measurements of the crossing vibrations of a railway turnout. Measurement 125:313-324

6. Chong L, Jiahong W, Zhixin Z, Junsheng L, Tongqun R, Hongquan X (2016) Design and evaluation of a remote measurement system for the online monitoring of rail vibration signals. Proc Inst Mech Eng Part F J Rail Rapid Transit 230(3):724-733

7. Oßberger U, Kollment W, Eck S (2017) Insight towards condition monitoring of fixed railway crossings. Procedia Struct Integr 4:106-114

8. Le Pen L, Milne D, Thompson D, Powrie W (2016) Evaluating railway track support stiffness from trackside measurements in the absence of wheel load data. Can Geotech J 53(7):1156-1166

9. Barkhordari P, Galeazzi R, de Miguel Tejada A, and Santos IF (2017) Low-complexity behavioral model for predictive maintenance of railway turnouts. In: Annual conference of the prognostics and health management society, Florida, USA

10. Barkhordari P, Galeazzi R, Blanke M (2020) Prognosis of railway ballast degradation for turnouts using track-side accelerations. Proc Inst Mech Eng Part O J Risk Reliab 234(4):601-610

11. Weston P, Roberts C, Yeo G, Stewart E (2015) Perspectives on railway track geometry condition monitoring from in-service railway vehicles. Veh Syst Dyn 53(7):1063-1091

12. Salvador P, Naranjo V, Insa R, Teixeira R (2016) Axlebox accelerations: Their acquisition and time-frequency characterisation for railway track monitoring purposes. Measurement 82:301-312

13. Kassa E, Nielsen J (2008) Dynamic interaction between train and railway turnout: full-scale field test and validation of simulation models. Veh Syst Dyn 46(sup1):521-534

14. Ekdahl G, Andersson L, Wrang M (2007) Instrumented wheelset technology—advances and applications, IHHA Specialist Technical Session (STS) Kiruna Sweden

15. Barke D, Chiu WK (2005) Structural health monitoring in the railway industry: a review. Struct Health Monitor 4(1):81-93

16. Kouroussis G, Caucheteur C, Kinet D, Alexandrou G, Verlinden O, Moeyaert V (2015) Review of trackside monitoring solutions: from strain gages to optical fibre sensors. Sensors 15(8):20115-20139

17. Karoumi R, Wiberg J, Liljencrantz A (2005) Monitoring traffic loads and dynamic effects using an instrumented railway bridge. Eng Struct 27(12):1813-1819

18. Bi L, Zhao P, Teng M, Zhao L, Liu X, Xin M (2020) Wayside testing methods for high-frequency vertical wheel-rail impact forces and its applicability. Measurement. https://doi.org/10. 1016/j.measurement.2019.107197

19. Cortis D, Bruner M, Malavasi G (2020) Development of a wayside measurement system for the evaluation of wheel-rail lateral contact force. Measurement. https://doi.org/10.1016/j. measurement.2020.107786

20. Xin L, Markine VL, Shevtsov IY (2016) Numerical analysis of the dynamic interaction between wheel set and turnout crossing using the explicit finite element method. Veh Syst Dyn 54(3):301-327

21. Wiedorn J, Daves W, Ossberger U, Ossberger H, Pletz M (2017) Simplified explicit finite element model for the impact of a wheel on a crossing-validation and parameter study. Tribol Int 111:254-264

22. SCode (Switch and Crossing Optimal Design and Evaluation) D3.1 (2019) Next generation control: monitoring and sensor systems, EU Shift2Rail S-Code project. http://www.s-code.info/ results-and-publications/. Accessed 21 Dec 2021

23. Skrypnyk R, Ekh M, Nielsen JCO, Pålsson BA (2019) Prediction of plastic deformation and wear in railway crossings-comparing the performance of two rail steel grades. Wear 428-429:302-314

24. Li X, Nielsen JCO, Pålsson BA (2014) Simulation of track settlement in railway turnouts. Veh Syst Dyn 52(sup1):421-439

25. Hixson EL (1997) Shock and Vibration Handbook (Chapter 10). In: Harris CM (ed) Mechanical impedance, 5th edn. McGraw Hill

26. Jenkins HH, Stephenson JE, Clayton GA, Morland GW, Lyon D (1974) The effect of track and vehicle parameters on wheel/rail vertical dynamic loads. IMechE Railw Eng J 3(1):2-16

27. Nielsen JCO, Ekberg A, Lunde R (2005) Influence of short-pitch wheel/rail corrugation on rolling contact fatigue of railway wheels. Proc IMechE Part F J Rail Rapid Transit 219(3):177-187

28. Nielsen J (2009) Wheel-rail interface handbook. In: Lewis R, Olofsson U (eds) Chapter 8: out-of-round railway wheels. Woodhead Publishing, pp 245-279

29. Torstensson PT, Squicciarini G, Krüger M, Pålsson BA, Nielsen JCO, Thompson DJ (2019) Wheel-rail impact loads and noise generated at railway crossings-influence of vehicle speed and crossing dip angle. J Sounds Vib 456:119-136

30. Johnson KL (1989) The strength of surfaces in rolling contact. Proc ImechE Part C J Mech Eng Sci 203(3):151-163

31. Rabbi MF, Johnson DK, Mishra D, Bruzek R (2009) Effect of track configuration and loading conditions on vertical wheel load measurements using the differential shear approach. Proc IMechE Part F J Rail Rapid Transit 26337(1):279-288

32. Milković D, Simić G, Jakovljević Ž, Tanasković J, Lučanin V (2013) Wayside system for wheel-rail contact forces measurements. Measurement 46(9):3308-3318

33. Du C, Dutta S, Kurup P, Yu T, Wang X (2020) A review of railway infrastructure monitoring using fiber optic sensors. Sens Actuators A Phys 303:66 